\title{
Research on Dynamic and Complexity of Duopoly Price Strategies between Low-Carbon and Nonlow-Carbon Products under Cap-and-Trade Policies
}

\author{
Ling Zhang (D) and Zheng Zhang (D) \\ Business School, University of Shanghai for Science and Technology, Shanghai 200093, China \\ Correspondence should be addressed to Zheng Zhang; 774112000@qq.com
}

Received 2 August 2021; Accepted 21 October 2021; Published 18 November 2021

Academic Editor: Marcelo Messias

Copyright (c) 2021 Ling Zhang and Zheng Zhang. This is an open access article distributed under the Creative Commons Attribution License, which permits unrestricted use, distribution, and reproduction in any medium, provided the original work is properly cited.

\begin{abstract}
This paper studies the complexity of the pricing system for the production of low-carbon and nonlow-carbon products in a market composed of duopoly manufacturers under the cap-and-trade policies. Through nonlinear system theory and numerical derivation and simulation, it considers the influence of different market power structures, carbon trading prices, consumer environmental awareness, and other factors on price decisions, carbon emission decisions, profits, and system stability. The influence of price adjustment parameters and unit product carbon emission decision adjustment parameters on the complexity of the pricing system under different market power structures is analyzed. And, it was found that compared with the variable feedback chaos control method, the parameter adjustment chaos control method is more effective in controlling the pricing system in this paper. Our research provides management implications for market competition and operational decision-making for low-carbon and nonlow-carbon products.
\end{abstract}

\section{Introduction}

In the past few decades, the impact of carbon emissions on the environment has become increasingly severe. Humans emit large amounts of carbon dioxide and other greenhouse gases to nature, which exceed the carrying and regulation capacity of the Earth, leading to an imbalance in the oceanland-atmosphere carbon cycle, the greenhouse gas concentration, and the Earth's temperature "double rise." For instance, atmospheric carbon dioxide concentration reached a record $415 \mathrm{ppm}$ in 2019. This has led to a significant increase in the frequency and intensity of extreme weather and climate events such as droughts, floods, hurricanes, wildfires, extreme heat, and severe cold in the atmosphere. To promote sustainable development, the government and scientists are committed to the coordinated development of the industrial economy and environment. Governments of different countries have promulgated various policies, including carbon emissions trading mechanisms, carbon emissions caps, carbon taxes, and so on $[1,2]$. These policies encourage manufacturers to be sustainable in the context of carbonconstrained policies and invest in low-carbon technologies to reduce carbon emissions throughout their production and operations [3].

The carbon cap-and-trade policy with market attributes is an efficient and sustainable development policy. The carbon trading mechanism has covered more than 40 countries worldwide. At present, the EU's carbon trading market has become the world's largest carbon trading market. Although a unified global carbon trading market has not yet been formed, different carbon trading markets have begun to connect with each other. The government's carbon allowance and trading policy is that the government allocates emission quotas or emission permits to pollutant-producing companies based on the emission level within a certain period of time. The government's carbon cap-and-trade policy is that the government allocates emission quotas or emission permits to pollutant producers based on emission 
levels within a period of time. If the company still has the remaining carbon allowance after the production is completed, it can be traded on the carbon trading market [4].

Government policies, corporate publicity, public environmental awareness, and consumer perceptions have increased the demand for low-carbon products. Consumers can buy products based on their low-carbon preferences $[5,6]$. Many companies reduce carbon emissions by improving internal operations, controlling the carbon footprint of the supply chain, and investing in low-carbon technologies. For example, Lenovo uses quantitative statistics on the carbon footprint of products to better optimize the environmental performance of products from the industrial chain. The chemical company, Huntsman is looking for effective ways to reduce carbon emissions in all links of the industrial chain, and empower the green and low-carbon transformation of the chemical industry. In 2019, the APP (China) launched a carbon inventory project for its forest land. As of 2020, the APP (China) has absorbed approximately 42.395 million tons of carbon dioxide. And, the APP (China) has sold a series of paper products related to carbon neutrality.

The pricing of low-carbon products is a significant issue in enterprises. Enterprise managers price products according to the factors such as the investment cost of carbon emission reduction, market demand, and procurement costs of the entire supply chain. Consumer environmental awareness (CEA) is one of the factors to be considered in product pricing. The meaning of CEA is similar to consumer sensitivity to low-carbon products and consumer low-carbon preference. CEA means that environmentally conscious consumers are more willing to buy low-carbon products (LP). The CEA first demonstrates in literature $[7,8]$ that consumers are more inclined to pay the price higher than nonlow-carbon products (NLP) when the product has low-carbon attributes. The technological innovation cost (TIC) is another major factor affecting the price of low-carbon products. However, the manufacturers of LP not only have to face TIC and CEA but also face the market competition with NLP [9].

The pricing of LP and NLP with alternative functions affects the supply and demand relationship and demand of all members in the supply chain. Pricing strategies in supply chains have been studied extensively [10-13]. Related to this research is mainly the product pricing problem under the duopoly market structure. The following is a brief review of relevant literature from the perspectives of static pricing and dynamic pricing.

Firstly, review the literature from the perspective of oneperiod static pricing. In reference [14], under the background of the carbon tax, the price decision of two manufacturers with different carbon emission reduction efficiencies was studied, and the impact of carbon tax on equilibrium decision-making was considered. The study found that in order to achieve a certain percentage of the expected carbon emissions reduction, the carbon tax imposed on efficiency manufacturers should be greater than that imposed on inefficiency companies. The study is one of the earliest papers to include government carbonrelated policies in the decision-making model; however, it ignores the impact of CEA on market demand. In reference [15], under the background of the carbon tax and carbon capand-trade policies, the authors compared the emission reduction decisions of the two manufacturers in the context of competition and cooperation. The research results show that under the carbon cap-and-trade policies, CEA affects manufacturers' carbon emissions. The research on the significant impact of CEA on the market can be found in references [16-18]. Therefore, the model established in this article considers the impact of CEA on market demand.

Reference [19] studied the price competition and internal carbon trading cooperation between two manufacturers with different production capacities under carbon emission constraints. Each manufacturer in the model has a fixed amount of carbon emissions, but does not consider carbon emission reduction. The results show that manufacturers with high production capacity have higher prices than other manufacturers. Luo and Chen [20] studied the optimal pricing and emission reduction policies of two competing manufacturers with different emission reduction efficiencies under the cap-and-trade policies. It has the same research purpose as literature [19], but it considers the market competition of manufacturers after carbon emission reduction. Literature [21] studied the product price decisions and low-carbon technology choices of two manufacturers with different carbon emissions under different carbon prices.

The above kinds of literature study the price competition problem between two manufacturers with different production efficiencies from the perspective of static game, but they do not consider market power structures. Market structure affects manufacturers' dynamic decisions and business strategies. Some previous studies on the power structure of the low-carbon supply chain market are [22-24].

The literature [25], under different market power structures, studied the optimal low-carbon investment and price decisions. It found that manufacturers who produce green products with high-efficiency emission reductions cannot guarantee high profits compared with inefficient manufacturers. The profits of manufacturers in a balance power market are not always lower than that of the leader in the market. The results are similar to references $[22,24]$. Lou and $\mathrm{Ma}$ [26] studied the decisions of manufacturers and retailers in price competition between two supply chains with different low-carbon efforts. They found that being the leader of the Stackelberg game often leads to more profits. This result is similar to [23].

We can get to know from the previous studies that under carbon-related policies, the influencing factors of manufacturers' profits under different power structures are complex, and market leaders may not be able to obtain more profits.

Except for [26], the above-mentioned literature studies are conducted from the perspective of static rational onecycle decision-making, while manufacturers cannot obtain complete information in the market. So, manufacturers change their pricing decisions based on changes in the collected information. The pricing system under complete information is unstable. Therefore, some researchers analyze 
the price game of duopoly manufacturers from the perspective of bounded rationality.

The dynamic game of bounded rational players has always been the focus of many types of research, focusing on Bertrand's duopoly game [27-29] and Cournot's game [30-32]. The literature [33] studied the dynamic price game model of a dual-channel green supply chain, considering the innovative investment of enterprises in green products and channel services. Zhao and Zhang [34] studied the dynamics pricing system involving two enterprises with heterogeneous expectation rules participating in carbon emission trading. The study found that the higher the carbon price, the higher the price for each enterprise. When the carbon price is too high, the Nash equilibrium will become unstable, and the system will enter a chaotic state through period-doubling bifurcation. The weakness of this study is that it adopts a linear emission reduction cost and does not consider the impact of the change of low-carbon emission reduction cost on the equilibrium decision.

Literature [35] considered government carbon taxes and subsidies, the price competition and system stability of fuel vehicles, and electric vehicles in different market power structures. Study results suggested that whether electric vehicles obtain the market's price leadership advantage depends on the cost difference between electric vehicles and fuel vehicles.

Existing literatures have studied product pricing between duopoly manufacturers with varying carbon emission reduction efficiencies, manufacturers with heterogeneous expectations, and carbon emission policies and market power structures between manufacturers with different carbon emission efficiencies. They provide a rich theoretical and model basis for this article. The comparison of existing models with this research is in Table 1.

Most of the above literatures consider the low-carbon emission reduction of a manufacturer or the upstream and downstream of the supply chain but seldom consider the impact of the manufacturer's low-carbon competitive environment and market power structure on low-carbon emission reduction and product price. Whether the vicious competition (low-carbon product and nonlow-carbon product) in the market will drive low-carbon manufacturers out of the market is less considered. And, the existing literature seldom considers the dynamic impact of government carbon allowances and carbon prices on the profits of manufacturers. Therefore, this paper uses nonlinear dynamic analysis to study the price competition of low-carbon products and nonlow-carbon products between duopoly manufacturers with different market power structures under the cap-and-trade policies. The research background is similar to references $[13,15]$.

The purpose of this study is to solve the following problems:

(1) What impact do different market power structures have on the decisions and profits of low-carbon product manufacturers and nonlow-carbon product manufacturers?

(2) What is the difference between the stable region of the system under different power structures? How do parameter changes that affect decision-making affect the size of the stability region of the system?

(3) How does the manufacturer's profit change under dynamic decision-making? What are the dynamic effects of carbon prices on manufacturers' profits?

(4) How to prevent the system from entering chaos? When entering a state of chaos, what methods can control the chaos?

So, our contribution in this paper can be concluded as follows:

(i) In a market where low-carbon products and nonlow-carbon products compete, we analyze the influence of the power structure between manufacturers on product prices, optimal carbon emissions, profits, and system stability.

(ii) The complexity of the low-carbon and nonlowcarbon product price competition system and the influencing factors of the system stability domain are analyzed.

(iii) We analyze the influence of changes in external carbon trading prices on the complexity of system profits.

(iv) We compared the two existing chaos control methods and explore a method that can effectively control the system's chaos.

The rest of the paper consists of the following parts: Section 2 introduces the model framework and assumptions with the interpretation of relevant symbols. We build the static game model and the dynamic game model. Analyze the optimal decision solution and the decision condition of system stability under different power structures, respectively. In Section 3, we explore the decision-making results of the model in Section 2 through numerical simulation. In Section 4, we analyze the complexity of the pricing system under the two power structures. In Section 5, we analyze the complexity of the impact of parameters on system profits. Section 6 analyses the typical characteristics of the nonlinear discrete system of pricing to better understand the complexity of the system. Section 7 compares the two chaos control methods and explores a chaos control method suitable for controlling the pricing system of this paper. Section 8 is the conclusion.

\section{Model}

2.1. Fundamental Assumptions and Notations. Under the government's carbon cap-and-trade policies, there are duopoly manufacturers producing similar functional products on the market. Duopoly competition in the past provides the theoretical basis for this paper [13, 34]. Among them, manufacturer $1\left(m_{1}\right)$ invests in low-carbon technology to produce low-carbon products (LP) and reduce carbon emissions in response to low-carbon emission reduction. In contrast, manufacturer $2\left(m_{2}\right)$ produces nonlow-carbon (NLP) products and competes with $m_{1}$ in price. There was little difference between the functions of LP and NLP, with 
TABLE 1: Comparison of existing models with this research.

\begin{tabular}{|c|c|c|c|c|}
\hline Authors & Background & Member of the chain & Decision variables & Method \\
\hline $\begin{array}{l}\text { Zhao and } \\
\text { Zhang [34] }\end{array}$ & Cap-and-trade & Two heterogeneous players & Retail price & $\begin{array}{c}\text { Game theory (Nash), } \\
\text { nonlinear dynamics }\end{array}$ \\
\hline $\begin{array}{l}\text { Chen and } \\
\text { Hao [14] }\end{array}$ & Carbon tax & $\begin{array}{l}\text { Two competing firms with } \\
\text { varying production } \\
\text { efficiencies }\end{array}$ & Retail price & Game theory (Nash) \\
\hline $\begin{array}{l}\text { Luo et al. } \\
{[20]}\end{array}$ & Cap-and-trade & $\begin{array}{l}\text { Two competing firms with } \\
\text { varying production } \\
\text { efficiencies }\end{array}$ & $\begin{array}{l}\text { Retail price, carbon emission index per } \\
\text { unit low-carbon product }\end{array}$ & Game theory (Nash) \\
\hline $\begin{array}{l}\text { Chen et al. } \\
{[25]}\end{array}$ & $\begin{array}{l}\text { Different market power } \\
\text { structures }\end{array}$ & $\begin{array}{l}\text { Two manufacturers with } \\
\text { varying production } \\
\text { efficiencies }\end{array}$ & $\begin{array}{l}\text { Retail price, carbon emission index per } \\
\text { unit low-carbon product }\end{array}$ & $\begin{array}{l}\text { Game theory (Nash and } \\
\text { Stackelberg) }\end{array}$ \\
\hline $\begin{array}{l}\text { Lou and } \\
\mathrm{Ma}[26]\end{array}$ & $\begin{array}{c}\text { Cap-and-trade, } \\
\text { different market power } \\
\text { structures }\end{array}$ & Two-parallel supply chain & $\begin{array}{l}\text { Retail price, manufacturers' wholesale } \\
\text { price, the carbon reduction effort, the } \\
\text { sales effort }\end{array}$ & $\begin{array}{c}\text { Game theory (Nash and } \\
\text { Stackelberg), nonlinear } \\
\text { dynamics }\end{array}$ \\
\hline $\begin{array}{l}\text { Jian et al. } \\
{[19]}\end{array}$ & Carbon emissions cap & $\begin{array}{l}\text { Two manufacturers with } \\
\text { varying production } \\
\text { efficiencies }\end{array}$ & Retail price & Game theory (Nash) \\
\hline $\begin{array}{l}\text { Wang and } \\
\text { Hou }[28]\end{array}$ & - & $\begin{array}{l}\text { A supplier }(\mathrm{M}) \text { and a } \\
\text { retailer }(\mathrm{S})\end{array}$ & $\begin{array}{l}\text { The green level of } M \text { and } S \text {, the } \\
\text { advertisement cost of } M \text {, the retail price }\end{array}$ & $\begin{array}{c}\text { Game theory } \\
\text { (Stackelberg), nonlinear } \\
\text { dynamics } \\
\end{array}$ \\
\hline $\begin{array}{l}\text { Ma et al. } \\
{[35]}\end{array}$ & $\begin{array}{c}\text { Different market power } \\
\text { structures, carbon tax } \\
\text { and subsidies }\end{array}$ & $\begin{array}{l}\text { Two manufacturers (electric } \\
\text { vehicle and the fuel vehicle) }\end{array}$ & Retail price & $\begin{array}{c}\text { Game theory } \\
\text { (Stackelberg), nonlinear } \\
\text { dynamics } \\
\end{array}$ \\
\hline Sana [13] & Tax and subsidies & $\begin{array}{l}\text { Two competing firms (green } \\
\text { and nongreen products) }\end{array}$ & $\begin{array}{c}\text { Retail price, carbon emission index per } \\
\text { unit low-carbon product, level of } \\
\text { corporate social responsibility (CSR) } \\
\text { activities et al. }\end{array}$ & Game theory (Nash) \\
\hline $\begin{array}{l}\text { Pan et al. } \\
{[21]}\end{array}$ & $\begin{array}{l}\text { Cap-and-trade, } \\
\text { subsidies }\end{array}$ & $\begin{array}{l}\text { Two manufacturers (dirtier } \\
\text { and environmentally } \\
\text { friendly) }\end{array}$ & $\begin{array}{l}\text { Retail price, a decision on whether to } \\
\text { implement green technology }\end{array}$ & Game theory (Nash) \\
\hline $\begin{array}{l}\text { Sun and } \\
\text { yang [15] }\end{array}$ & $\begin{array}{l}\text { Carbon tax, cap-and- } \\
\text { trade }\end{array}$ & $\begin{array}{l}\text { Two manufacturers } \\
\text { producing low-carbon } \\
\text { products } \\
\end{array}$ & $\begin{array}{l}\text { Carbon tax rate, carbon emission, } \\
\text { reduction per unit of product, carbon cap } \\
\text { allocated by government }\end{array}$ & Game theory (Nash) \\
\hline $\begin{array}{l}\text { Present } \\
\text { paper }\end{array}$ & $\begin{array}{c}\text { Cap-and-trade, } \\
\text { different market power } \\
\text { structures }\end{array}$ & $\begin{array}{l}\text { Two manufacturers (low- } \\
\text { carbon product and nonlow- } \\
\text { carbon product) }\end{array}$ & $\begin{array}{l}\text { Retail price, carbon emission index per } \\
\text { unit low-carbon product }\end{array}$ & $\begin{array}{c}\text { Game theory (Nash and } \\
\text { Stackelberg), nonlinear } \\
\text { dynamics }\end{array}$ \\
\hline
\end{tabular}

packaging indicating the carbon footprint of each unit of product produced or used. For example, in the Chinese market, Coca-Cola and Pepsi present duopoly competition in the cola market. If Coca-Cola revealed that producing a bottle of Coke had a lower carbon footprint than PepsiCo, they could enter a new round of price competition.

We make the following model assumptions to support this study.

Assumptions 1. The price competition between them is a long-term, repetitive, dynamic, and complex process. The information obtained by the manufacturer that affects the product price is limited. The manufacturers have bounded rationality and make the next decision rely on a local estimate of marginal utility for the current period. If the marginal utility is positive in this period, the selling price will be raised in the next period. Otherwise, the manufacturers will lower the selling price in the next period [24].
Assumptions 2. Due to the maturity of technology, the manufacturer's cost per unit product is $c$; the cost of supply chain emission reduction with the feature of convexity [26] is $\gamma\left(e_{0}-e_{1}\right)^{2}$. Where it satisfies the $q_{i}>0, p_{i}>0$ condition, then $\gamma>\left(\left(\left(\beta+p_{c}\right)\left(p_{c}+p_{c} \alpha+2 \beta\right)\right) / 2(2+\alpha)\right), p_{c}>\beta>0$.

Assumptions 3. Market demand is a function of the product price and carbon emissions, following similar arguments in studies [36]. Manufacturer 1 produces the low-carbon product (LP). Manufacturer 2 produces the nonlow-carbon product (NLP) and competes with manufacturer 1 on price. The optimal carbon emissions of unit LP is less than the initial carbon emissions with the low-carbon technology production, that is, $0<e_{1}<e_{0}$. The parameters and meanings used in this paper are shown in Table 2.

2.2. Model Construction. The relationship between the manufacturers is not certain. We consider two kinds of market power situations. One is that in the balance market, 
TABle 2: Parameters and variables.

\begin{tabular}{|c|c|c|}
\hline \multicolumn{3}{|r|}{ Parameters } \\
\hline No & Notation & Definition \\
\hline 1 & $a$ & Potential market size \\
\hline 2 & $\alpha(0<\alpha<1)$ & Cross-price sensitivity coefficient of two products \\
\hline 3 & $\beta(0<\beta<1)$ & The CEA parameter \\
\hline 4 & $\gamma$ & The TIC parameter (cost coefficient for green technology to reduce carbon emission compared to $e_{0}$ ) \\
\hline 5 & $e_{0}$ & Carbon emission index per unit nonlow-carbon product \\
\hline 6 & $c$ & Manufacturing cost per unit of the product \\
\hline 7 & $p_{c}$ & Carbon emissions trading price \\
\hline 8 & $E$ & Carbon caps \\
\hline 9 & $q_{i}$ & Market demands of the product $i$ \\
\hline 10 & $u_{1}$ & Manufacturer 1's price adjustment speed \\
\hline 11 & $u_{2}$ & Manufacturer 1's carbon emissions adjustment speed \\
\hline 12 & $u$ and $v$ & The system's adaptive parameters adjustment speed \\
\hline \multicolumn{3}{|r|}{ Decision variables } \\
\hline 1 & $p_{1}$ & The price of low-carbon product \\
\hline 2 & $p_{2}$ & The price of nonlow-carbon product \\
\hline 3 & $e_{1}\left(0<e_{1}<e_{0}\right)$ & Carbon emission index per unit low-carbon product \\
\hline \multicolumn{3}{|r|}{ Other variables and abbreviations } \\
\hline 1 & $n l$ & Nash game (balance market) \\
\hline 2 & $m_{1} l$ & The Stackelberg game of manufacturer 1 is the leader (unbalance market) \\
\hline 3 & $\prod_{i}(i=1,2)$ & The profit of manufacturer $i$ \\
\hline 4 & LP & Low-carbon product \\
\hline 5 & NLP & Nonlow-carbon product \\
\hline 6 & $m_{1}$ & Manufacturer 1 (produces LP) \\
\hline 7 & $m_{2}$ & Manufacturer 2 (produces NLP) \\
\hline 8 & CEA & Consumer environmental awareness \\
\hline 9 & TIC & Technological innovation cost \\
\hline
\end{tabular}

two manufacturers have the same market position. We establish the Nash game model for price competition in the balance market $(n l)$. The other is that the $m_{1}$ is the leader in the unbalance market. So we establish a Stackelberg game $\left(m_{1} l\right)$. Then, we compare the results under the two kinds of the market power structures.

2.2.1. Nash Game ( $n l)$. In the $n l$ game, there is no leader in the two manufacturers, and the decision order is that the manufacturers decide product price $p_{i}$ and the optimal carbon emission level at the same time.

Based on the assumption in Section 2.1, the market demand is not only affected by the product price but also by the carbon emission of the product and the consumers' environmental awareness [37]. Taking the above factors into consideration, the market demand of the product can be depicted as follows [38]:

$$
\left\{\begin{array}{l}
q_{1}=a-p_{1}+\alpha p_{2}-\beta\left(e_{1}-e_{0}\right), \\
q_{2}=a-p_{2}+\alpha p_{1}-\beta\left(e_{0}-e_{1}\right) .
\end{array}\right.
$$

$\beta$ denotes the parameter of CEA, similar to references [16-18]. Equation (1) shows that the market demand for LP increases with parameter $\beta$ increasing and $e_{0}-e_{1}$ is the reduced carbon emissions of LP. With $\beta$ constant, the market demand for LP increases with $m_{1}$ reducing carbon emissions. This means that compared with NLP, the lower the carbon emissions of LP, the easier it is to attract consumers to buy them. Furthermore, the potential market demand and cross-price sensitivity coefficient are, respectively, $a$ and $\alpha$. The $\alpha$ is the interactive effect of prices between LP and NLP in the market. The interactive impact of price is lower than the impact of the product's price on demand. Therefore, we assume that the product's price sensitivity coefficient is 1 and $0<\alpha<1$.

Therefore, the manufacturer's profit expression is as follows:

$$
\left\{\begin{array}{l}
\prod_{1}=\left(p_{1}-c-p_{c} e_{1}\right) q_{1}-\gamma\left(e_{0}-e_{1}\right)^{2}+p_{c} E \\
\prod_{2}=\left(p_{2}-c-p_{c} e_{0}\right) q_{2}+p_{c} E .
\end{array}\right.
$$

In equation (2), $\prod_{1}$ is the profit of the LP manufacturer. $\prod_{2}$ is the profit of the NLP manufacturer. So $\prod_{1}$ has a low-carbon innovation cost, where $\gamma\left(e_{0}-e_{1}\right)^{2} \gamma$ is the cost coefficient for green technology to reduce carbon emission compared to $e_{0}$ [13]. And $E$ is the maximum carbon emission allocated by the government to the manufacturers. If the manufacturer's total carbon emissions exceed the government's carbon cap, $p_{c} e_{n} q_{n}(n=0,1)>p_{c} E$, the manufacturer needs to purchase carbon emissions from the market. Therefore, the environmental cost of the product paid by the manufacturer is $p_{c} e_{n} q_{n}-p_{c} E(n=0,1) . p_{c}$ is the carbon price in the carbon trading market.

Then, the first-order partial derivatives of $\prod_{1}$ and $\prod_{2}$ with respect to $p_{1}, e_{1}$ and $p_{2}$, respectively, can be calculated: 


$$
\left\{\begin{array}{l}
\frac{\partial \prod_{1}}{\partial p_{1}}=a+c-2 p_{1}+e_{1} p_{c}+p_{2} \alpha-\beta\left(e_{1}-e_{0}\right) \\
\frac{\partial \prod_{1}}{\partial e_{1}}=\left(c-p_{1}+e_{1} p_{c}\right) \beta+2\left(e_{0}-e_{1}\right) \gamma-p_{c}\left(a-p_{1}+p_{2} \alpha-\beta\left(e_{1}-e_{0}\right)\right) \\
\frac{\partial \prod_{2}}{\partial p_{2}}=a+c-2 p_{2}+e_{0} p_{c}+p_{1} \alpha-\beta\left(e_{0}-e_{1}\right)
\end{array}\right.
$$

In addition, according to the marginal profit of $m_{2}$ in equation (3), the optimal reaction function of $m_{2}$ can be obtained as follows:

$$
p_{2}^{*}(t)=\frac{1}{2}\left(a+c+e_{0} p_{c}+p_{1} \alpha-e_{0} \beta+e_{1} \beta\right) .
$$

Taking the second-order derivatives of equation (3), we can get the profit of $m_{1}$ 's Hessian matrix of $p_{1}$ and $e_{1}$ as follows:

$$
H\left(\prod_{1}\right)=\left[\begin{array}{cc}
-2 & p_{c}-\beta \\
p_{c}-\beta & 2 p_{c} \beta-2 \gamma
\end{array}\right] .
$$

Obviously, the value of principal minors of the Hessian matrix, $\left|H_{1}\left(\prod_{1}\right)\right|=-2$ is negative and based on Assumption 2, $\quad \gamma>\left(\left(\left(\beta+p_{c}\right)\left(p_{c}+p_{c} \alpha+2 \beta\right)\right) / 2(2+\alpha)\right)$, then the $\left|H_{2}\left(\prod_{1}\right)\right|=4\left(\gamma-p_{c} \beta\right)-\left(p_{c}-\beta\right)^{2}>0 H\left(\prod_{1}\right)$ is negative definite. It assures $\prod_{1}$ is concave. Therefore, $m_{1}$ can obtain the optimal market price and carbon emissions that maximize profits.

Proposition 1. we get the optimal price $p_{1}, p_{2}$ and the optimal carbon emission $e_{1}$ by letting equation (3) equal to zero. Solution can be obtained as follows:

$$
\left\{\begin{array}{l}
p_{1}^{*}(n l)=\frac{-\left(A_{1}^{n l}+A_{2}^{n l}+A_{3}^{n l}-A_{4}^{n l}\right)}{p_{c}^{2}\left(\alpha^{2}-2\right)-2\left(\alpha^{2}-4\right) \gamma+\beta^{2}(\alpha-2)+p_{c} \beta(\alpha(\alpha+1)-4)} \\
e_{1}^{*}(n l)=\frac{B_{1}^{n l}-B_{2}^{n l}}{p_{c}^{2}\left(\alpha^{2}-2\right)-2\left(\alpha^{2}-4\right) \gamma+\beta^{2}(\alpha-2)+p_{c} \beta(\alpha(\alpha+1)-4)} \\
p_{2}^{*}(n l)=\frac{C_{1}^{n l}+C_{2}^{n l}-a C_{3}^{n l}}{p_{c}^{2}\left(\alpha^{2}-2\right)-2\left(\alpha^{2}-4\right) \gamma+\beta^{2}(\alpha-2)+p_{c} \beta(\alpha(\alpha+1)-4)}
\end{array}\right.
$$

Please refer $A_{i}^{n l}, B_{i}^{n l}$, and $C_{i}^{n l}(i=1,2, \ldots, 4)$ in Appendix A.
Therefore, substituting equations (6) into (2), we can obtain the optimal profits of $m_{1}$ and $m_{2}$ under the Nash game as follows:

$$
\left\{\begin{array}{l}
\prod_{1}^{*}(n l)=\frac{-(2+\alpha)^{2}\left(p_{c}+\beta\right)^{2} \gamma D_{1}^{n l}+D_{2}^{n l}+D_{3}^{n l}}{\left(p_{c}^{2}\left(\alpha^{2}-2\right)-2\left(\alpha^{2}-4\right) \gamma+\beta^{2}(\alpha-2)+p_{c} \beta(\alpha(\alpha+1)-4)\right)^{2}} \\
\prod_{2}^{*}(n l)=\frac{D_{1}^{n l}\left(C_{3}^{n l}\right)^{2}}{\left(p_{c}^{2}\left(\alpha^{2}-2\right)-2\left(\alpha^{2}-4\right) \gamma+\beta^{2}(\alpha-2)+p_{c} \beta(\alpha(\alpha+1)-4)\right)^{2}}+E p_{c} .
\end{array}\right.
$$

Please refer $D_{i}^{n l}(i=1,2,3)$ in Appendix B

According to the assumptions: For the feasibility of the model $0<e_{1}<e_{0}$ and the $e_{1}^{*}(n l)$ in equation (6), when there is an optimal carbon emission reduction for $m_{1}$, the range of $e_{0}$ can be obtained as follows:

$$
\frac{(a+c(\alpha-1))(2+\alpha)\left(p_{c}+\beta\right)}{8 \gamma-\alpha\left(p_{c}^{2}-\beta^{2}+2 \alpha \gamma\right)-2 \beta\left(p_{c}+\beta\right)}<e_{0}<\frac{a+c(\alpha-1)}{p_{c}(1-\alpha)} .
$$

Now, we establish a dynamic game model. The game between $m_{1}$ and $m_{2}$ is a long-term, repetitive, and complex dynamic adjustment process [29]. Thus, decision-making 
based on bounded rationality is common in practice [34, 39]. So, we build the dynamic game model as follows:

$$
\left\{\begin{array}{l}
p_{1}(t+1)=p_{1}(t)+\mu_{1} p_{1}(t) \frac{\partial \pi_{1}(t)}{\partial p_{1}(t)}, \\
e_{1}(t+1)=e_{1}(t)+\mu_{2} e_{1}(t) \frac{\partial \pi_{1}(t)}{\partial e_{1}(t)}, \\
p_{2}(t+1)=p_{2}^{*}(t),
\end{array}\right.
$$

where $\mu_{1}$ and $\mu_{2}$, respectively, represent the adjustment speed of $p_{1}$ and $e_{1}$, which are affected by many factors, such as the learning ability, decision-making ability, and management ability of the whole decision-making organization. The optimal reaction function in each decision period $(t)$ determines the variable decision in the next period $(t+1)$.

Combing equations (3), (4), and (9), we can obtain a nonlinear discrete dynamic equation as follows:

$$
\left\{\begin{array}{l}
p_{1}(t+1)=p_{1}(t)+u_{1} p_{1}(t)\left(a+c-2 p_{1}(t)+e_{1} p_{c}+p_{2}(t) \alpha-\beta\left(e_{1}-e_{0}\right)\right), \\
e_{1}(t+1)=e_{1}(t)+u_{2} e_{1}(t)\left(\left(c-p_{1}(t)+e_{1}(t) p_{c}\right) \beta t+n 2 q\left(e_{0}-e_{1}(t)\right) h \gamma_{-} x p_{c} 7\left(a-p_{1}(t)+p_{2} \alpha-\beta\left(e_{1}(t)-e_{0}\right)\right)\right), \\
p_{2}(t+1)=\frac{1}{2}\left(a+c+e_{0} p_{c}+p_{1}(t) \alpha-e_{0} \beta+e_{1}(t) \beta\right) .
\end{array}\right.
$$

$m_{1}$ makes decisions for the next period according to the current marginal profit situation. The decision of $m_{2}$ differs from that of $m_{1}$, which makes decisions based on the complete rationality of profit maximization.
Let $\quad p_{1}(t+1)=p_{1}(t), \quad e_{1}(t+1)=e_{1}(t) \quad$ and $p_{2}(t+1)=p_{2}(t)$; then, we could directly get four equilibrium solutions of mapping (10), described by

$$
\left\{\begin{array}{l}
E_{1}=\left(0,0, \frac{1}{2}\left(a+c+e_{0} p_{c}-e_{0} \beta\right)\right), \\
E_{2}=\left(0, \frac{a p_{c}(2+\alpha)+c\left(p_{c} \alpha-2 \beta\right)+e_{0}\left(p_{c}^{2} \alpha+p_{c}(2-\alpha) \beta+4 \gamma\right)}{p_{c}(4-\alpha) \beta-4 \gamma}, \frac{a\left(2 \gamma-3 p_{c} \beta+2 \gamma\right)+c\left(\beta^{2}-2 p_{c} \beta+2 \gamma\right)+p_{c} e_{0}\left(\beta^{2}-2 p_{c} \beta+2 \gamma\right)}{p_{c}(\alpha-4) \beta+4 \gamma}\right), \\
E_{3}=\left(\frac{e_{0} p_{c} \alpha+a(2+\alpha)+c(2+\alpha)-e_{0}(\alpha-2) \beta}{4-\alpha^{2}}, 0, \frac{2 e_{0} p_{c}+a(2+\alpha)+c(2+\alpha)+e_{0}(\alpha-2) \beta}{4-\alpha^{2}}\right), \\
E^{*}(n l)=\left(p_{1}^{*}(n l), e_{1}^{*}(n l), p_{2}^{*}(n l)\right) .
\end{array}\right.
$$

Notice that $E_{i}(i=1,2,3)$ are boundary instability equilibrium solutions, while $E^{*}(n l)$ is the only Nash equilibrium solution [40]. Its expression is shown in equation (6). In our model, we just consider two manufacturers, and both carried on the competition. So, $E_{i}(i=1,2,3)$ is not taken into consideration.

Based on the result, we can obtain the Jacobian matrix of system (10) as follows:

$$
J(n l)=\left[\begin{array}{ccc}
1+u_{1} h_{1} & u_{1} p_{1}\left(p_{c}-\beta\right) & p_{1} u_{1} \alpha \\
e_{1} u_{2}\left(p_{c}-\beta\right) & 1-u_{2} h_{2} & -e_{1} u_{2} p_{c} \alpha \\
\frac{\alpha}{2} & \frac{\beta}{2} & 0
\end{array}\right]
$$

where

$$
\begin{aligned}
h_{1}= & a+c-4 p_{1}+e_{1}\left(p_{c}-\beta\right)+p_{2} \alpha+e_{0} \beta, \\
h_{2}= & p_{c}\left(a+p_{2} \alpha\right)-p_{1}\left(p_{c}-\beta\right)-\beta\left(c+4 e_{1} p_{c}-e_{0} p_{c}\right) \\
& -2 \gamma\left(e_{0}+2 e_{1}\right) .
\end{aligned}
$$

Put $E^{*}(n l)$ into the Jacobian matrix (12) to obtain the Jacobian matrix to study the local stability of Nash equilibrium. The characteristic equation of the Jacobian matrix is

$$
f(\lambda)=\lambda^{3}+A \lambda^{2}+B \lambda+C,
$$

where 


$$
\begin{aligned}
& A=-2-u_{1} h_{1}+u_{2} h_{2}, \\
& B=\frac{1}{2}\left(2-2 h_{2} u_{2}-2 h_{1} u_{1}\left(-1+h_{2} u_{2}\right)-p_{1} u_{1} \alpha^{2}+e_{1} u_{2}\left(-2 p_{1} u_{1}\left(p_{c}-\beta\right)^{2}+p_{c} \alpha \beta\right)\right), \\
& C=-\frac{1}{2} \alpha\left(e_{1} p_{c}\left(1+h_{1} u_{1}\right) u_{2} \beta+p_{1} u_{1}\left(e_{1} u_{2}\left(p_{c}-\beta\right) \beta+\alpha\left(-1+u_{2}\left(h_{2}+e_{1} p_{c}\left(-p_{c}+\beta\right)\right)\right)\right)\right) .
\end{aligned}
$$

The stability of the system is based on the Jury stability criterion [41], and the equation is as follows:

$$
\left\{\begin{array}{l}
f(1)=A+B+C+1>0 \\
-f(-1)=-A+B-C+1>0 \\
C^{2}-1<0 \\
\left(1-C^{2}\right)^{2}-(B-A C)^{2}>0
\end{array}\right.
$$

According to condition (16), we can obtain the stable region of the dynamic system (10) on adjustment parameters $\mu_{1}$ and $\mu_{2}$. Due to the complexity of solving the stability conditions of the system, it is impossible to accurately express the range of the stability region by mathematical means. In the next section, we express the stability region and the changes of related parameters by computer mathematical analysis.
2.2.2. Stackelberg Game $\left(m_{1} l\right)$. When $m_{1}$ produces LP, it may have a much stronger voice in the market under the cap-and-trade policies and gain a leadership position in the price competition [35]. Here, we also want to analyze this situation.

In the $m_{1} l$ model, $m_{1}$ is the leader, while $m_{2}$ is the follower. The decision order is that $m_{1}$ determines the product price $p_{1}$ and optimal carbon emission $e_{1}$ according to the maximization of its profit, and then $m_{2}$ determines the product price $p_{2}$.

According to the classic backward induction, substituting the equations (4) into (2) and then taking the first-order partial derivatives of $\prod_{1}$ with respect to $p_{1}$ and $e_{1}$, we can get

$$
\left\{\begin{array}{l}
\frac{\partial \prod_{1}}{\partial p_{1}}=a-p_{1}-\frac{1}{2}\left(c-p_{1}+e_{1} p_{c}\right)\left(-2+\alpha^{2}\right)-e_{1} \beta+e_{0} \beta+\frac{1}{2} \alpha\left(a+c+e_{0} p_{c}+p_{1} \alpha-e_{0} \beta+e_{1} \beta\right) \\
\frac{\partial \prod_{1}}{\partial e_{1}}=2\left(e_{0}-e_{1}\right) \gamma-\frac{1}{2}\left(c-p_{1}+e_{1} p_{c}\right) \beta(\alpha-2)-p_{c}\left(a-p_{1}-e_{1} \beta+e_{0} \beta+\frac{1}{2} \alpha\left(a+c+e_{0} p_{c}+p_{1} \alpha-e_{0} \beta+e_{1} \beta\right)\right)
\end{array}\right.
$$

Taking the second-order derivatives further, we can get the Hessian matrix:

$$
H\left(\prod_{1}\right)=\left[\begin{array}{cc}
-2+\alpha^{2} & -p_{c}\left(\frac{\alpha^{2}}{2}-1\right)-\beta+\frac{\alpha \beta}{2} \\
-p_{c}\left(\frac{\alpha^{2}}{2}-1\right)-\beta+\frac{\alpha \beta}{2} & -2 \gamma-2 p_{c}\left(-\beta+\frac{\alpha \beta}{2}\right)
\end{array}\right] .
$$

Obviously, the value of principal minors of the Hessian matrix, $\left|H_{1}\left(\prod_{1}\right)\right|=-2+\alpha^{2}$, is negative and based on
Assumption $2 \gamma>\left(\left(\left(\beta+p_{c}\right)\left(p_{c}+p_{c} \alpha+2 \beta\right)\right) / 2(2+\alpha)\right)$, then $\left|H_{2}\left(\prod_{1}\right)\right|=-(1 / 4)\left(p_{c}\left(-2+\alpha^{2}\right)+(-2+\alpha) \beta\right)^{2}-2\left(-2+\alpha^{2}\right)$ $\gamma>0 H\left(\prod_{1}\right)$ is negative definite. It assures $\prod_{1}$ is concave. Then, $m_{1}$ can obtain the optimal market price and carbon emissions.

Proposition 2. We get the optimal price $p_{1}$ and $e_{1}$ by letting equation (17) equal to zero. Furthermore, substituting the optimal price $p_{1}$ and $e_{1}$ into equation (4) for $p_{2}$, we have the optimal price $p_{1}^{*}\left(m_{1} l\right), p_{2}^{*}\left(m_{1} l\right)$, and optimal carbon emission $e_{1}^{*}\left(m_{1} l\right)$ :

$$
\left\{\begin{array}{l}
p_{1}^{*}\left(m_{1} l\right)=\frac{A_{1}^{m_{1} l}+A_{2}^{m_{1} l}+A_{3}^{m_{1} l}}{\left(p_{c}^{2}\left(\alpha^{2}-2\right)^{2}+8\left(\alpha^{2}-2\right) \gamma+2 p_{c}\left(\alpha^{2}-2\right) \beta(\alpha-2)+\beta^{2}(\alpha-2)^{2}\right)} \\
e_{1}^{*}\left(m_{1} l\right)=\frac{B_{1}^{m_{1} l}-B_{2}^{m_{1} l}+B_{3}^{m_{1} l}}{\left(p_{c}^{2}\left(\alpha^{2}-2\right)^{2}+8\left(\alpha^{2}-2\right) \gamma+2 p_{c}\left(\alpha^{2}-2\right) \beta(\alpha-2)+\beta^{2}(\alpha-2)^{2}\right)} \\
p_{2}^{*}\left(m_{1} l\right)=\frac{C_{1}^{m_{1} l}-a C_{2}^{m_{1} l}+C_{3}^{m_{1} l}}{p_{c}^{2}\left(\alpha^{2}-2\right)^{2}+8\left(\alpha^{2}-2\right) \gamma+2 p_{c}\left(\alpha^{2}-2\right) \beta(\alpha-2)+\beta^{2}(\alpha-2)^{2}}
\end{array}\right.
$$


Please refer $A_{i}^{m_{1} l}, B_{i}^{m_{1} l}$, and $C_{i}^{m_{1} l}(i=1,2, \ldots, 4)$ in Appendix C.
Substituting equation (19) into equation (2), we can obtain the optimal profit of $m_{1}$ and $m_{2}$ as follows:

$$
\left\{\begin{array}{l}
\prod_{1}^{*}\left(m_{1} l\right)=E p_{c}-\frac{(2+\alpha)^{2} \gamma\left(a+c(\alpha-1)+e_{0} p_{c}(\alpha-1)\right)^{2}}{\left(p_{c}^{2}\left(\alpha^{2}-2\right)^{2}+8\left(\alpha^{2}-2\right) \gamma+2 p_{c}\left(\alpha^{2}-2\right) \beta(\alpha-2)+\beta^{2}(\alpha-2)^{2}\right)^{2}} \\
\prod_{2}^{*}\left(m_{1} l\right)=E p_{c}+\frac{\left(a+c(\alpha-1)+e_{0} p_{c}(\alpha-1)\right)^{2}\left(C_{2}^{m_{1} l}\right)^{2}}{\left(p_{c}^{2}\left(\alpha^{2}-2\right)^{2}+8\left(\alpha^{2}-2\right) \gamma+2 p_{c}\left(\alpha^{2}-2\right) \beta(\alpha-2)+\beta^{2}(\alpha-2)^{2}\right)^{2}}
\end{array}\right.
$$

According to the assumption: $0<e_{1}<e_{0}$ and the $e_{1}^{*}\left(m_{1} l\right)$ in equation (19), when there is an optimal carbon emission reduction for $m_{1}$, the range of $e_{0}$ can be obtained as follows:

$$
\frac{(a+c(\alpha-1))(2+\alpha)\left(p_{c}\left(\alpha^{2}-2\right)+\beta(\alpha-2)\right)}{4 \beta^{2}+p_{c} \beta\left(\alpha^{3}+4-3 \alpha^{2}\right)+\alpha^{2}\left(8 \gamma+\beta^{2}\right)-p_{c}^{2} \alpha\left(\alpha^{2}-2\right)-16 \gamma-4 \alpha \beta^{2}}<e_{0}<\frac{a+c(\alpha-1)}{p_{c}(1-\alpha)}
$$

Similar to the model $n l$, we build a dynamic Stackelberg game model as follows:

$$
\left\{\begin{array}{l}
p_{1}(t+1)=p_{1}(t)+u_{1} p_{1}(t) \frac{\partial \prod_{1}(t)}{\partial p_{1}(t)} \\
e_{1}(t+1)=e_{1}(t)+u_{2} e_{1}(t) \frac{\partial \prod_{1}(t)}{\partial e_{1}(t)} \\
p_{2}(t+1)=\frac{1}{2}\left(a+c+e_{0} p_{c}+p_{1}(t) \alpha-e_{0} \beta+e_{1}(t) \beta\right) .
\end{array}\right.
$$

System (22) gives the manufacturer's dynamic price decision. The decision variables directly relate to the positive parameter $\mu_{1}$ and $\mu_{2}$ which represents the adjustment speed of $p_{1}$ and $e_{1} \cdot\left(\partial \prod_{1}(t) / \partial p_{1}(t)\right)$ and $\left(\partial \prod_{1}(t) / \partial e_{1}(t)\right)$ are the marginal profit, which can be obtained by equation (17).

Combining equations (17) and (22), a nonlinear discrete dynamic equation of the system is obtained as

$$
\left\{\begin{array}{l}
p_{1}(t+1)=p_{1}(t)+u_{1} p_{1}(t)\left(a-p_{1}-\frac{1}{2}\left(c-p_{1}+e_{1} p_{c}\right)\left(-2+\alpha^{2}\right)-e_{1} \beta+e_{0} \beta+\frac{1}{2} \alpha\left(a+c+e_{0} p_{c}+p_{1} \alpha-e_{0} \beta+e_{1} \beta\right)\right) \\
e_{1}(t+1)=e_{1}(t)+u_{2} e_{1}(t)\left(2\left(e_{0}-e_{1}\right) \gamma-\frac{1}{2}\left(c-p_{1}+e_{1} p_{c}\right) \beta(\alpha-2)-p_{c}\left(a-p_{1}-e_{1} \beta+e_{0} \beta+\frac{1}{2} \alpha\left(a+c+e_{0} p_{c}+p_{1} \alpha-e_{0} \beta+e_{1} \beta\right)\right)\right) \\
p_{2}(t+1)=\frac{1}{2}\left(a+c+e_{0} p_{c}+p_{1}(t) \alpha-e_{0} \beta+e_{1}(t) \beta\right) .
\end{array}\right.
$$


Therefore, let $p_{1}(t+1)=p_{1}(t), e_{1}(t+1)=e_{1}(t)$ and $p_{2}(t+1)=p_{2}(t)$; then, we could directly get four equilibrium solutions of mapping (23), described by

$$
\left\{\begin{array}{l}
E_{1}=\left(0,0, \frac{1}{2}\left(a+c+e_{0} p_{c}-e_{0} \beta\right)\right) \\
E_{2}=\left(0, \frac{a p_{c}(2+\alpha)+c\left(p_{c} \alpha+(\alpha-2) \beta\right)+e_{0}\left(p_{c}^{2} \alpha+p_{c}(2-\alpha) \beta-4 \gamma\right)}{2 p_{c}(2-\alpha) \beta-4 \gamma}, \frac{a\left(p_{c}(\alpha-6) \beta+4 \gamma\right)+\left(c+e_{0} p_{c}\right)\left(p_{c}(-4+\alpha) \beta-(\alpha-2) \beta^{2}+4 \gamma\right)}{4 p_{c}(\alpha-2) \beta+8 \gamma}\right) \\
E_{3}=\left(\frac{e_{0} p_{c}\left(\alpha^{2}-4\right)+a\left(\alpha^{2}-2 \alpha-4\right)+c\left(\alpha^{3}+\alpha^{2}-2 \alpha-4\right)-e_{0}\left(\alpha^{2}+2 \alpha-4\right) \beta}{4\left(\alpha^{2}-2\right)}, 0, \frac{2 e_{0} p_{c}+a(2+\alpha)+c(2+\alpha)+e_{0}(\alpha-2) \beta}{4-\alpha^{2}}\right) \\
E^{*}\left(m_{1} l\right)=\left(p_{1}^{*}\left(m_{1} l\right), e_{1}^{*}\left(m_{1} l\right), p_{2}^{*}\left(m_{1} l\right)\right)
\end{array}\right.
$$

Notice that $E_{i}(i=1,2,3)$ are boundary equilibrium solutions, while $E^{*}\left(m_{1} l\right)$ is the solution that meets the purpose of this article with economic significance. Its expression is shown in (19)

The Jacobian matrix of system (23) is given by

$$
J\left(m_{1} l\right)=\left[\begin{array}{cc}
1+p_{1} u_{1}\left(\alpha^{2}-2\right)+u_{1} h_{3} & -\frac{1}{2} p_{1} u_{1}\left(p_{c}\left(\alpha^{2}-2\right)+\beta(2-\alpha)\right) \\
-\frac{1}{2} e_{1} u_{2}\left(p_{c}\left(\alpha^{2}-2\right)+\beta(2-\alpha)\right) & 1-\frac{1}{2} u_{2} h_{4}
\end{array}\right],
$$

where

$$
\begin{aligned}
& h_{3}=a-p_{1}-\frac{1}{2}\left(c-p_{1}+e_{1} p_{c}\right)\left(\alpha^{2}-2\right)+\beta\left(e_{0}-e_{1}\right)+\frac{1}{2} \alpha\left(a+c+e_{0}\left(p_{c}-\beta\right)+p_{1} \alpha+e_{1} \beta\right), \\
& h_{4}=\left(c p_{c}+e_{0} p_{c}^{2}\right) \alpha+a p_{c}(2+\alpha)+2 \beta\left(e_{0} p_{c}-c-4 e_{1} p_{c}\right)+\beta\left(c \alpha+p_{c}\left(4 e_{1} \alpha-e_{0}\right)\right)-p_{1}\left((\alpha-2) \beta-p_{c}\left(\alpha^{2}-2\right)\right)-4 \gamma\left(e_{0}-2 e_{1}\right) .
\end{aligned}
$$

We can determine the stability of the equilibrium by the Jacobian matrix at the equilibrium point. Put $E^{*}\left(m_{1} l\right)$ into equation (25) to obtain the Jacobian matrix of the discrete dynamic system. The characteristic equation of the Jacobian matrix is

$$
f(\lambda)=\lambda^{2}-\operatorname{Tr}(J) \lambda+\operatorname{Det}(J)
$$

where

$$
\begin{aligned}
\operatorname{Tr}(J) & =2+h_{3} u_{1}-\frac{h_{4} u_{2}}{2}+p_{1} u_{1}\left(-2+\alpha^{2}\right), \\
\operatorname{Det}(J) & =\frac{1}{4}\left(4-2 h_{4} u_{2}-2 h_{3} u_{1}\left(-2+h_{4} u_{2}\right)-p_{1} u_{1}\left(8-4 \alpha^{2}+2 h_{4} u_{2}\left(-2+\alpha^{2}\right)+e_{1} u_{2}\left(p_{c}\left(-2+\alpha^{2}\right)-(-2+\alpha) \beta\right)^{2}\right)\right) .
\end{aligned}
$$


According to the Jury stability criterion [41], the Jury stability criterion of the system $(23)$ at $E^{*}\left(m_{1} l\right)$ can be expressed as follows:

$$
\left\{\begin{array}{l}
1+\operatorname{Tr}(J)+\operatorname{Det}(J)>0 \\
1-\operatorname{Tr}(J)+\operatorname{Det}(J)>0 \\
1-\operatorname{Det}(J)>0
\end{array}\right.
$$

Based on eigenvalues of the Jacobian matrix, the stability and bifurcation of the system (23) will be studied in detail in the next section by numerical simulation.

2.3. Influence of Different Market Power Structures on Decision-Making. This section compares optimal product price, profit, and carbon emissions per unit product under different market power structures.

Table 3 compares the optimal decisions and profits of $m_{1}$ and $m_{2}$ under the two market power structures. In $m_{1} l$, the equilibrium price of the product is greater than that in game $n l$, and the optimal carbon emission per unit product by $m_{1}$ in $m_{1} l$ is higher than that in $n l$. Manufacturer's profits in game $m_{1} l$ is greater than that in game $n l$. However, comparing demand under the two market power structures, $m_{1}$ and $m_{2}$ are opposite in market demand.

We can find that a balanced market power structure is more conducive to the spread of low-carbon products and the development of low-carbon technology. Still, it is not conducive to the profit of low-carbon manufacturers.

The profit under the unbalanced market is greater than the profit under the balanced market is the same as that in reference [25] but contrary to the conclusion of reference [26]. This article believes that in single-cycle decision-making, the influence of market power structure on the profits of market participants is complicated. The profits need to be determined according to models established in different environments.

The price, demand, and profit of $m_{2}$ in unbalanced market are higher than those in balanced market power structure. In the duopoly game where LP and NLP compete, for $m_{2}$, who produce the NLP, the best strategy is to be a follower of the market.

Under the balanced market structure, the comparison of the equilibrium prices of LP and NLP is related to the carbon price in the market. This result is the same as [14]. However, under the unbalanced market, comparison of LP and NLP prices is affected by the $p_{c}, \alpha$, and $\beta$ parameter, and the result is more complicated and cannot be deduced.

\section{Static Numerical Simulation Analysis}

In Sections 2 and 3, we build and figure out the model. This section analyzes the correlation between CEA and TIC parameters and decision variables through numerical simulation.

Parameter values are set as follows: $p_{c}=1, \alpha=0.5, \beta=$ $0.5, \gamma=3, c=5, a=10, e_{0}=8, E=11$. The parameter value satisfies the assumptions. We use numerical simulation analysis methods to study the complex effects of related parameters on system decision-making.
TABle 3: Comparison of optimal decisions and profits of the two models.

\begin{tabular}{lcc}
\hline & $m_{1}$ & $m_{2}$ \\
\hline$p_{i}$ & $p_{1}^{*}\left(m_{1} l\right)>p_{1}^{*}(n l)$ & $p_{2}^{*}\left(m_{1} l\right)>p_{2}^{*}(n l)$ \\
$\prod_{i}$ & $\prod_{1}^{*}\left(m_{1} l\right)>\prod_{1}^{*}(n l)$ & $\prod_{2}^{*}\left(m_{1} l\right)>\prod_{2}^{*}(n l)$ \\
$e_{1}$ & $e_{1}^{*}\left(m_{1} l\right)>e_{1}^{*}(n l)$ & - \\
$q_{i}$ & $q_{1}^{*}(n l)>q_{1}^{*}\left(m_{1} l\right)$ & $q_{2}^{*}\left(m_{1} l\right)>q_{2}^{*}(n l)$ \\
\hline
\end{tabular}

We can observe from Figure 1(a) that the optimal decision price $p_{1}$ when $m_{1}$ as leader in the unbalance market is greater than that in the balance market. An increase in the parameter $\gamma$ leads to an increase in $p_{1}$ and $\gamma$ affects the size of the correlation between $p_{1}$ and $\beta$. From Figure 1(b), we can get that the optimal decision price of $m_{2}$ as a follower in the unbalance market is greater than that in the balance market and $\gamma$ is negatively correlated with $p_{2} . \gamma$ affects the correlation between $p_{2}$ and $\beta$. As $\gamma$ increases, the sensitivity of $p_{2}$ to $\beta$ decreases and $p_{2}$ is always negatively correlated with $\beta$. However, $p_{1}$ is not always positively correlated with $\beta$.

From Figure 1(c), carbon emissions per unit in a balanced market are lower than that in an unbalanced market. $\beta$ and $e_{1}$ are negatively correlated, and $\gamma$ affects the magnitude of the correlation between $\beta$ and $e_{1}$.

From the above numerical simulation, we can get that when CEA changes, leading to $m_{1}$ adjustment of the LP price, the current innovation cost TIC must be considered. The price of LP does not necessarily increase with the increase of CEA. But, the price of NLP decreases with the increase of CEA. LP's carbon emissions decrease with the increase of CEA. The numerical simulation results are the same as the numerical comparison results in Section 2.3.

From Figures 2(a) and 2(b), we get that the profits of the manufacturers in the unbalanced market are higher than that in the balanced market. Low-carbon $m_{1}$ 's profit is positively correlated with $\beta$ and negatively correlated with $\gamma$, and $m_{2}$ 's profit is just the opposite. When $\gamma$ decreases, the price of LP decreases, and the increase in market demand brings increased profits to $m_{1}$. At the same time, it affects the reduction of $m_{2}$ 's profit.

\section{Dynamic Game Complexity Analysis}

From the simulation in the third section, we know the correlation between the relevant parameters of the system and the decision variables. In Section 4, through the bifurcation diagram, largest Lyapunov exponents (LLEs), we analyze the influence of parameters and adjustment speed of decision variables on the dynamic system. Study the complex behaviour of the pricing system to better understand the dynamic characteristics of market competition.

4.1. Influence of Parameters on the Stability Region. In this section, according to equations (29) and (16), we get the influence of CEA and TIC on the stability region of the system. In the stable region, no matter what the initial price is, after a finite number of games, the product's price will stabilize at Nash equilibrium. When the manufacturers 


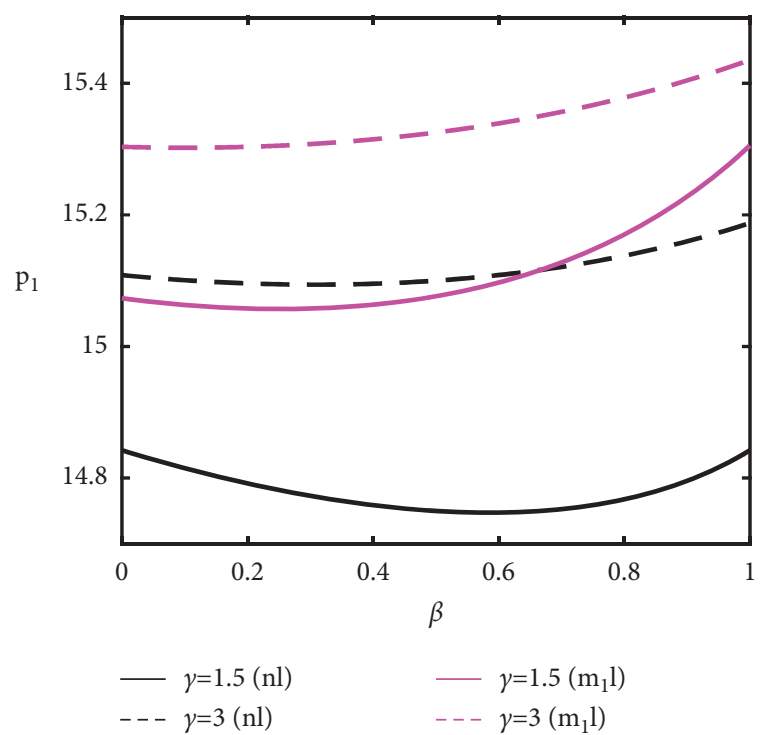

(a)

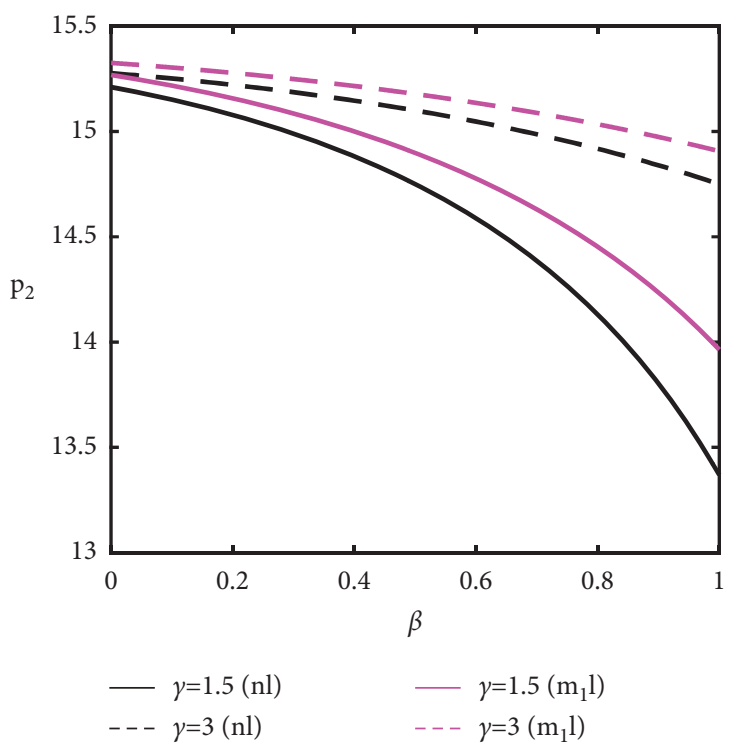

(b)

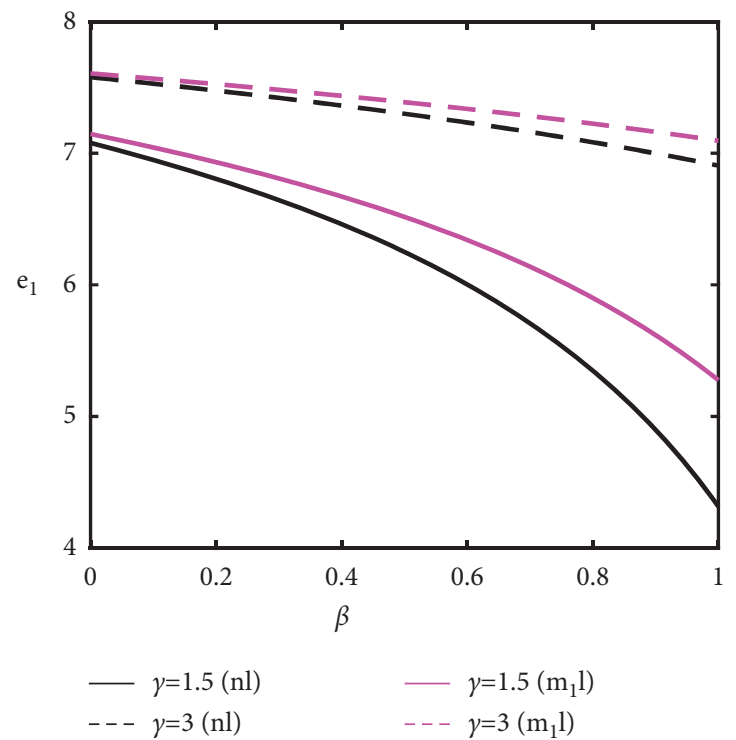

(c)

Figure 1: The impact of $\beta$ and $\gamma$ on price and $e_{1}$. (a) The impact of $\beta$ and $\gamma$ on $p_{1}$. (b) The impact of $\beta$ and $\gamma$ on $p_{2}$. (c) The impact of $\beta$ and $\gamma$ on $e_{1}$.

adjust parameters beyond the stable region, the stability of the Nash equilibrium point will change, and the phenomenon of bifurcation and chaos will appear.

Figures 3(a) and 3(b) show the stable region of system $p_{1}$ and $e_{1}$ adjustment speed under different $\beta$ and $\gamma$ parameters. The price adjustment speed parameter $u_{1}$ stability range in $m_{1} l$ is larger than that in $n l$. But the carbon emission adjustment speed parameter's $u_{2}$ stability range in $n l$ is larger than that in $m_{1} l$. This is different from the literature [42] that the Stackelberg game's parameter stability region is greater than that in the Nash game. With $\beta$ increased, the $u_{2}$ adjustment stability range increased. And, the stability region of the system decreases with the $\gamma$ increasing. The stability range of $u_{2}$ is more sensitive to the $\gamma$ changing than that of $u_{1}$. When $\gamma$ decreases, the stability range of $u_{2}$ increases more than the stability range of $u_{1}$.

From the comprehensive analysis of Figures 1-3, we can get that when the TIC remains unchanged and the CEA increases, the unit carbon emissions of LP decrease. At this time, the carbon emission adjustment speed stability region increases, and manufacturers can quickly adjust carbon emissions per unit LP according to the increase in CEA. CEA increase is beneficial to $m_{1}$ 's profit. But, it should be noted that the increase in CEA does not significantly increase the stability range of $u_{1}$, so the price adjustment speed cannot exceed the range of the stability range. And, if the CEA increases, whether the LP price increases or decreases depends on the size of the cost of low-carbon innovation. 


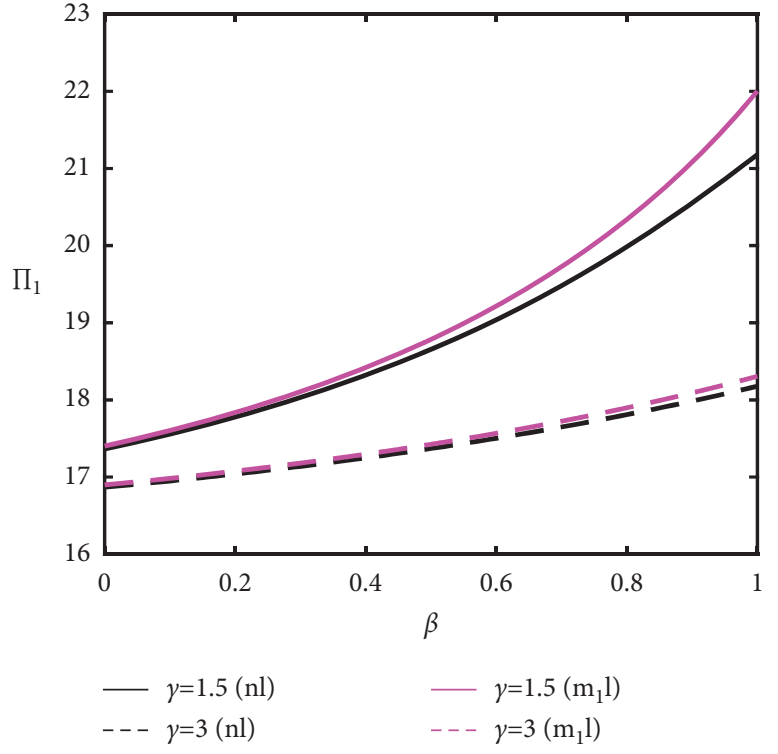

(a)

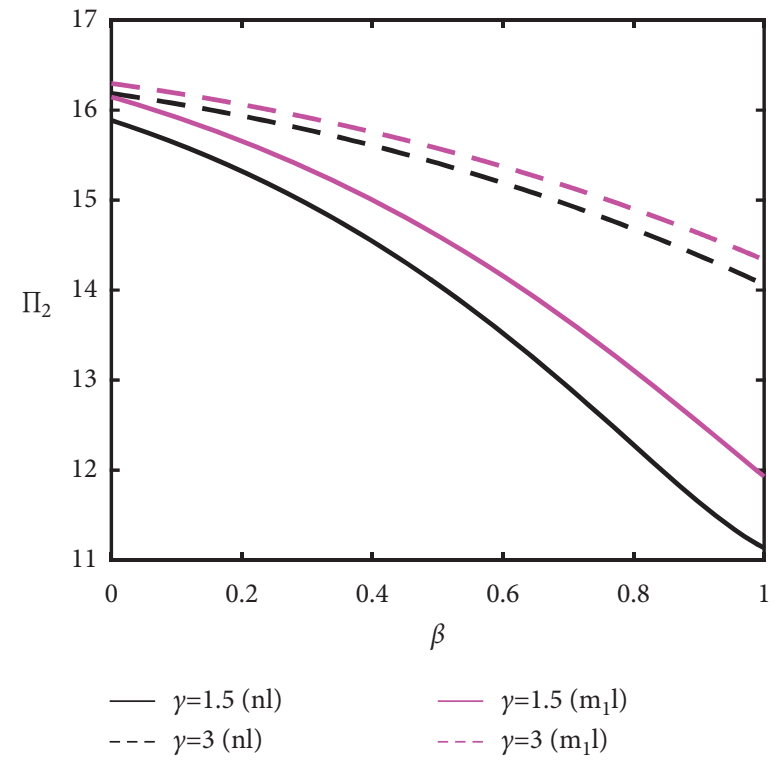

(b)

Figure 2: The impact of $\beta$ and $\gamma$ on profit. (a) The impact of $\beta$ and $\gamma$ on $\prod_{1}$. (b) The impact of $\beta$ and $\gamma$ on $\prod_{2}$.

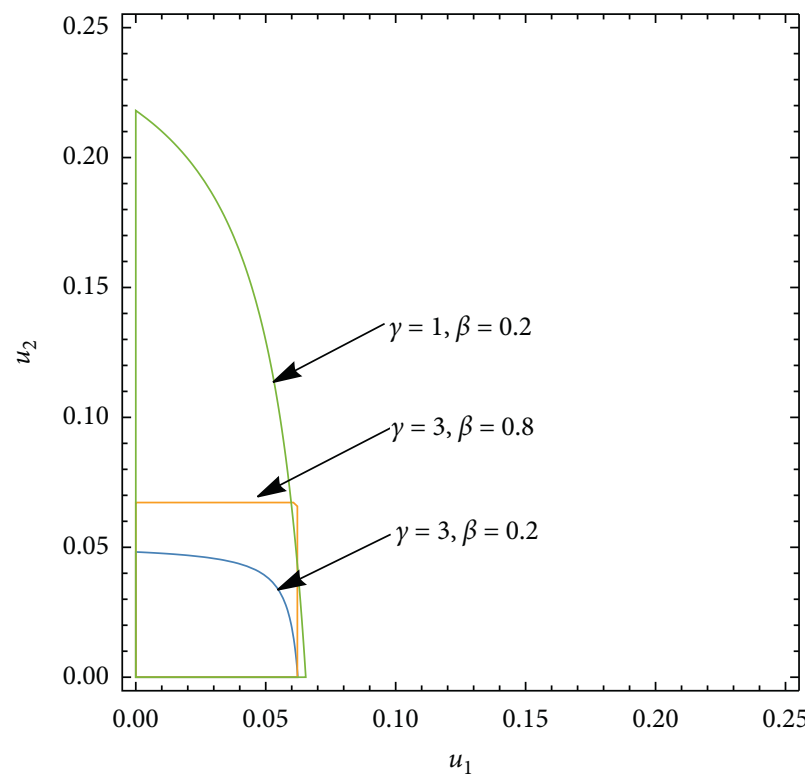

(a)

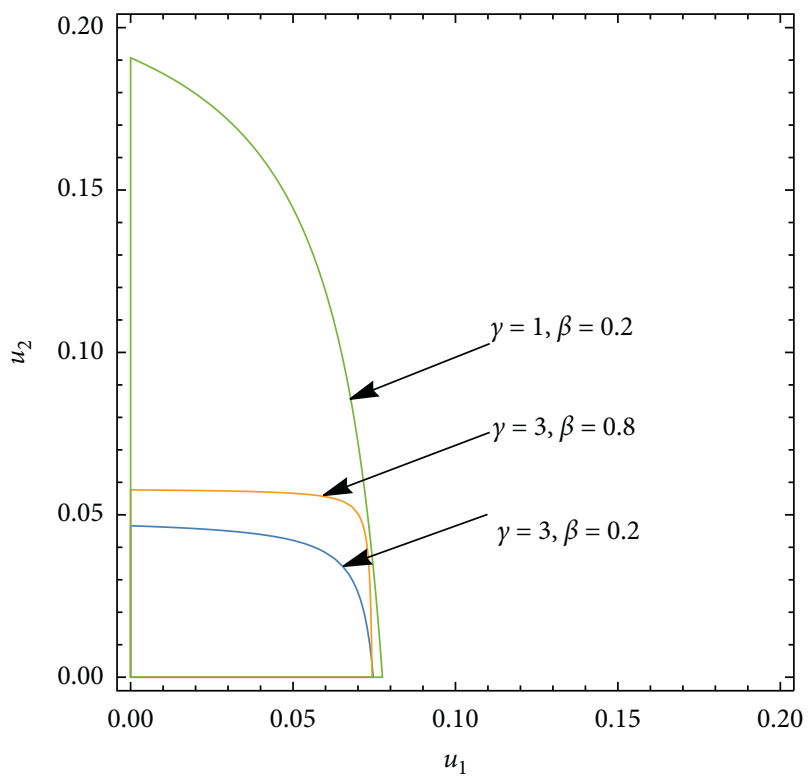

(b)

Figure 3: The influence of parameters on the stability region of the system. (a) $n l$ system. (b) $m_{1} l$ system.

4.2. System Complexity Analysis. This section analyzes the complexity of the system through bifurcation diagrams and Lyapunov exponents. We give the bifurcation diagram to analyze the bifurcation types of the system, the periodic properties of the solutions, and the path leading to chaos [43]. Figure 4 presents the dynamic evolution process of the dynamic system (10) with $u_{2}=0.02$. From Figure $4(\mathrm{a})$, we can see that when $u_{1}$ is in the stability range, the system (10) is in a stable state. With increasing $u_{1}$, the dynamic system (10) has the first bifurcation and then falls into the chaos through a series of period-doubling bifurcations.
Figure 4(b) is the diagram of the largest Lyapunov exponent (LLE), which indicates the system's state. When the maximum Lyapunov index is less than zero, the system is stable. When the maximum Lyapunov index equals zero, the system begins to bifurcate. When the maximum Lyapunov is greater than zero, the system is in chaotic [44]. When the Lyapunov exponent of Figure 4(b) $u_{1}$ in the range of $0.08-0.09$ has some points close to zero, Figure 4(a) has periodic windows in chaos. Figures 5(a) and 5(b), respectively, show the bifurcation diagram and the LLE of the system (23) with $u_{1}$ increasing. 


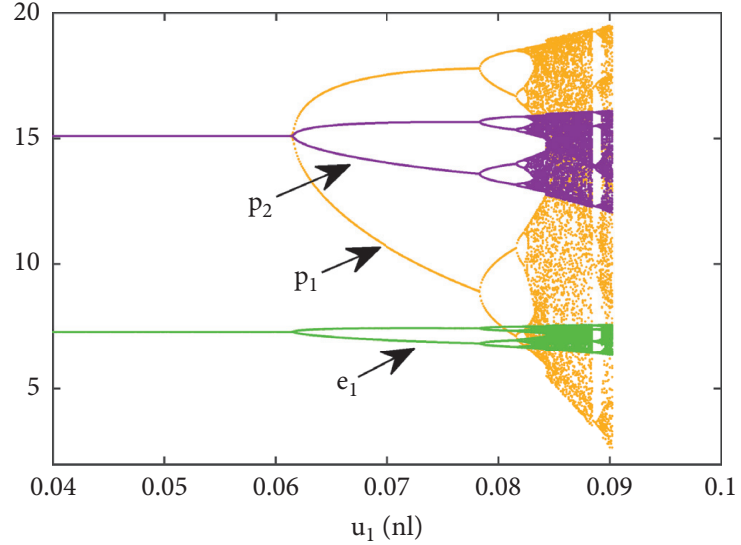

(a)

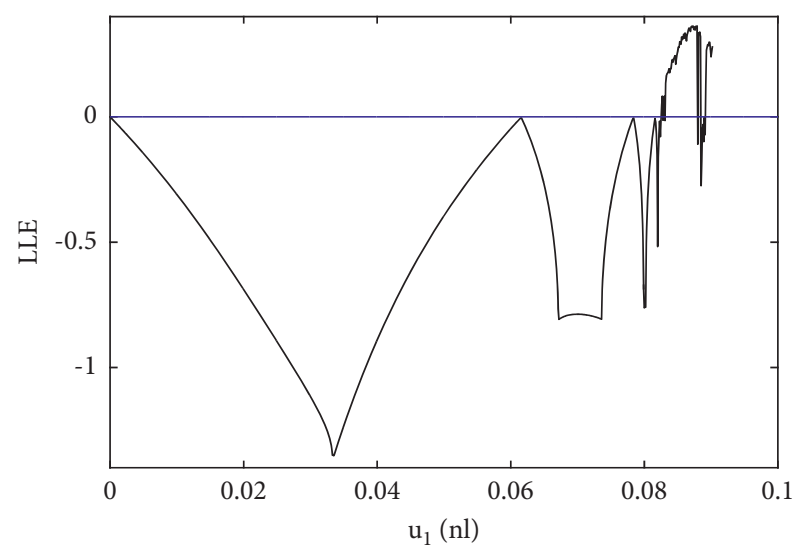

(b)

FIgURE 4: (a) Bifurcation diagram and (b) LLE of the system (10) with varying $u_{1}$ when $u_{2}=0.02$.

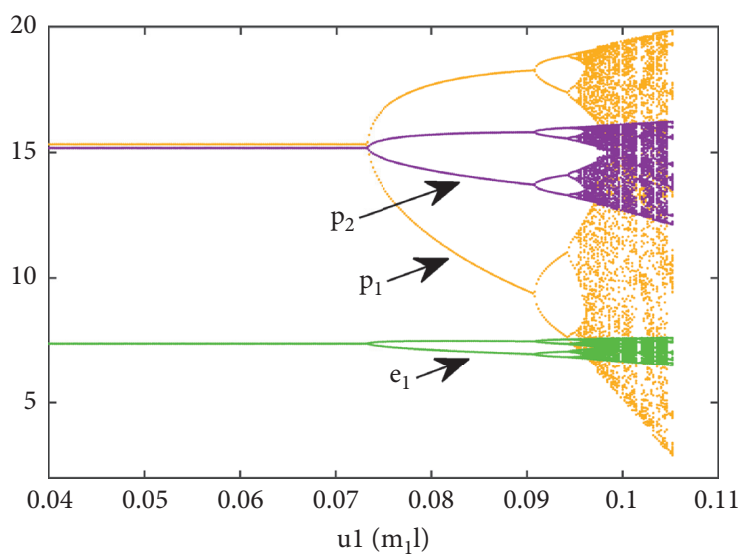

(a)

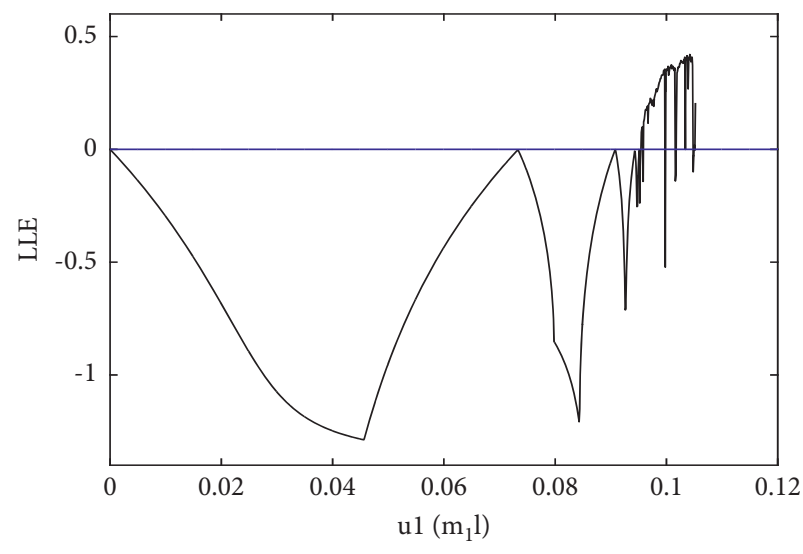

(b)

Figure 5: (a) Bifurcation diagram and (b) LLE of the system (23) with varying $u_{1}$ when $u_{2}=0.02$.

So, we can see that when both systems are in chaos, it is more difficult for low-carbon $m_{1}$ to control the price of LP. In the chaotic state, the optimal price fluctuation range of $m_{1}$ is greater than that of $m_{2}$. Therefore, in the chaotic state, $m_{1}$ is more difficult to control prices than $m_{2}$. When systems are in chaos, the optimal carbon emissions of LP are still less than the initial carbon emissions of the product. The stable range of $u_{1}$ in system (23) is greater than that in the system (10).

Figure 6 is the 2D bifurcation diagram of the system (10) regarding the adjusted speeds of $u_{1}$ and $u_{2}$. Different colours in a $2 \mathrm{D}$ bifurcation diagram indicate that the system is in different periods (the colour displayed by the colour bar on the right side of the bifurcation diagram). The grey represents quasiperiodic or chaotic, and the white represents the escape state, the three states that cannot be calculated. We can get from the figure that the system has two paths into chaos. The first is through the green region (1-period) $\longrightarrow$ the purple region (2-period) $\longrightarrow$ the yellow region (4-period) $\longrightarrow$ the crimson region (8-period) and finally enters the grey region losing stability through periodic bifurcation. There is a special periodic bifurcation phenomenon in Figure 6(c) that the system will fall into 6period orbits (dark blue) after 4-period state and then after that, the system falls into chaos. The second is that enter the grey region through the green region (1-period) and the purple region (2-period) system loses stability through $\mathrm{N}-\mathrm{S}$ bifurcation and then enters chaos through periodic bifurcation. After entering the N-S bifurcation, the system may enter 6-period (dark blue) and 10-period orbits (light pink), and finally enter chaos.

Figures 6(a) and 6(b) compare, as the parameter $\alpha$ increases, the stable region of $u_{2}$ increases, and the stable region of $u_{1}$ decreases. The path of the system into the chaotic state has not changed. Figures $6(\mathrm{~b})$ and $6(\mathrm{c})$ compare, with the increase of the parameter $p_{c}$, the stability region of $u_{2}$ increases, and the stability region of $u_{1}$ decreases. The 10-period (light pink) orbit in Figure 6(b) disappears in Figure 6(c), and when $u_{1}$ is small, increasing $u_{2}$ will make $p_{1}$ stay on the 2 -period orbit instead of entering chaos. Figures $6(\mathrm{~b})$ and $6(\mathrm{~d})$ compare, with the increase of parameter $\beta$, the stable region of $u_{2}$ increases, and the stable region of $u_{1}$ is almost unchanged, which is the same as the conclusion in Figure 3. System (23) has the 


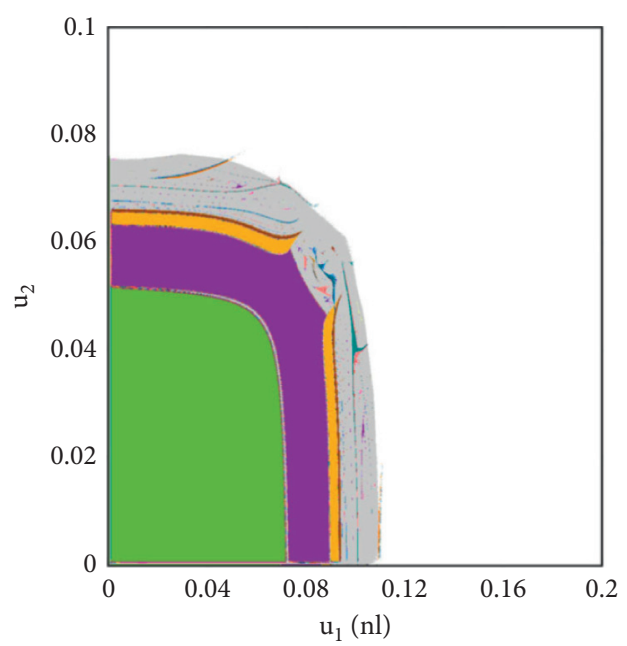

(a)

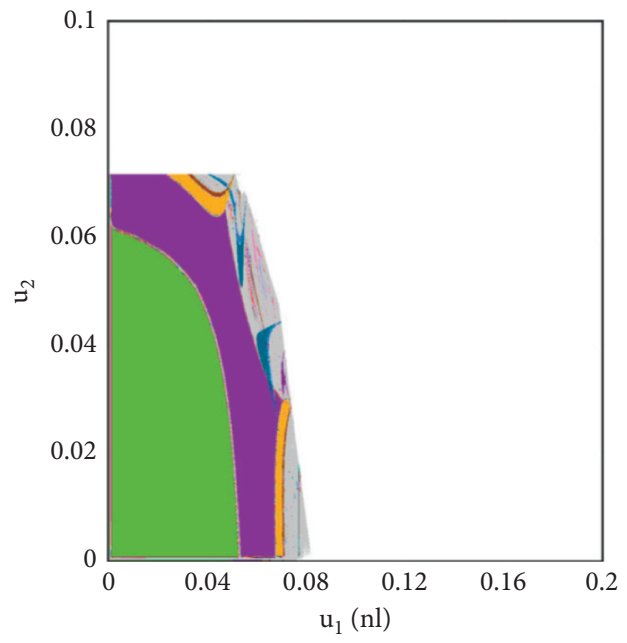

(c)
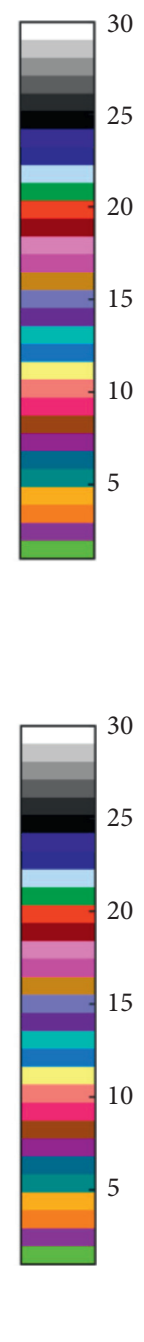

Figure 6: The 2-D bifurcation diagram of system (10). (a) $\alpha=0.3, p_{c}=1, \beta=0.5$, (b) $\alpha=0.5, p_{c}=1, \beta=0.5,(\mathrm{c}) \alpha=0.5, p_{c}=1.5, \beta=0.5$, and (d) $\alpha=0.5, p_{c}=1, \beta=0.3$.

same path into chaos as the system (10), and changes in the stability region of the system under the influence of parameters $\alpha, \beta$, and $\gamma$ are the same. The analysis is omitted here.

From the above analysis, we get that, first, under the slight changes of different parameters, the path of the system into chaos may undergo complex changes. Secondly, the increase of parameters $\alpha, \beta$, and $p_{c}$ is conducive to the stable region of $u_{2}$, but not conducive to the stable region of $u_{1}$. Finally, in price and carbon emissions management, when the cross-price sensitivity and carbon prices increase, manufacturers should reduce the speed of price adjustments and pay attention to the stable region of carbon emissions adjustment speed. When consumers' environmental awareness increases, it can be observed from Figure 2(a) that the marginal profit of $m_{1}$ is greater than zero, and $m_{1}$ is facing an increase in price. It should be noted that the stability region of price adjustment speed does not change with the change of $\beta$.

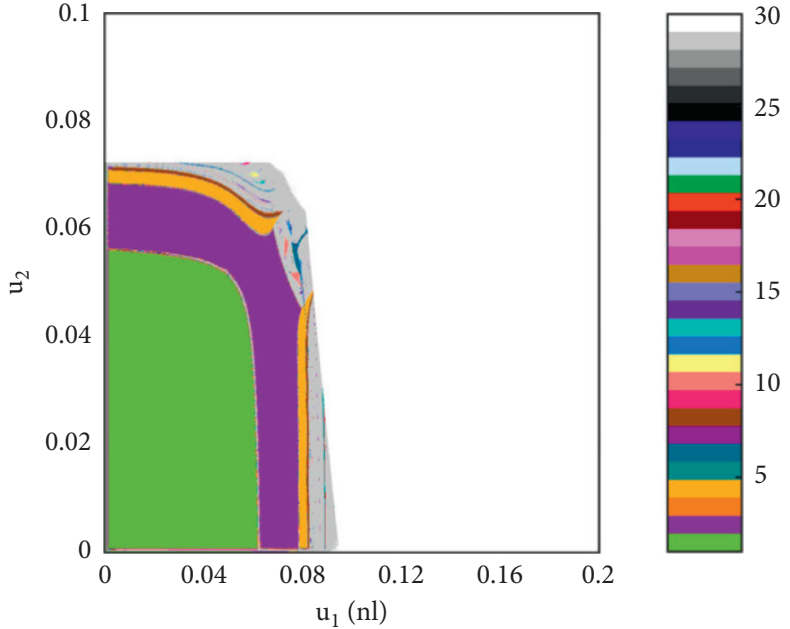

(b)
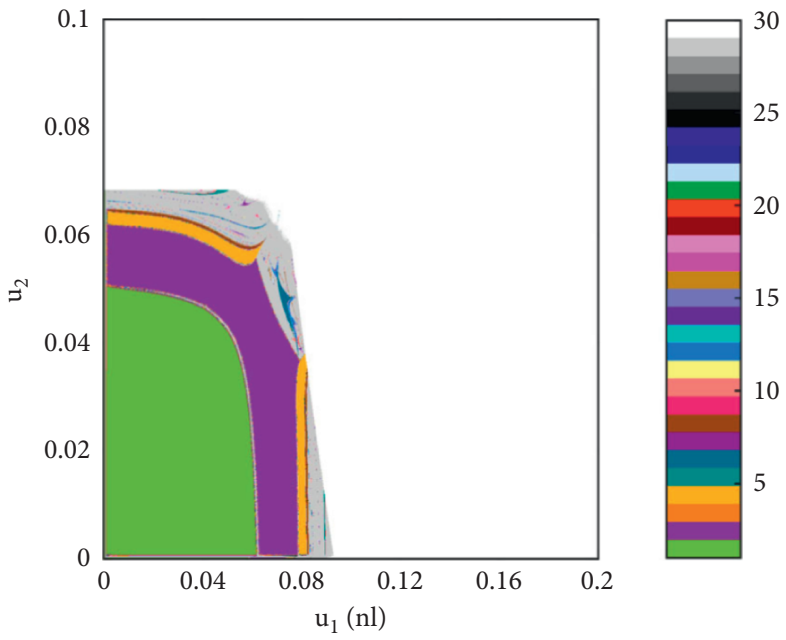

(d)

\section{Influence of Parameters on the Profits}

Under the carbon cap-and-trade policies, the profits of manufacturers are affected by carbon prices. So, this section considers the impact of parameters $u_{1}, u_{2}$, and $p_{c}$ on profits.

5.1. Impact of $u_{1}$ and $u_{2}$ on Profit. In this section, we get the simulation analysis of the influence of $u_{1}$ and $u_{2}$ on profit. Figures 7 (a) and $7(\mathrm{~b})$, respectively, show the average profit of the manufacturer under the changes of the parameters $u_{1}$ and $u_{2}$. We can observe that the average profit in the chaotic state is less than the profit in the stable state. As the price adjustment speed parameter $u_{1}$ increases, the average profit of $m_{1}$ in the chaotic state decreases significantly (black and green lines in the figure). In the chaotic state, the influence of $u_{1}$ on profit is greater than the influence of $u_{2}$ on profit. The profit of NLP manufacturers with rational expectations is more stable than that of LP manufacturers with bounded rational expectations. 


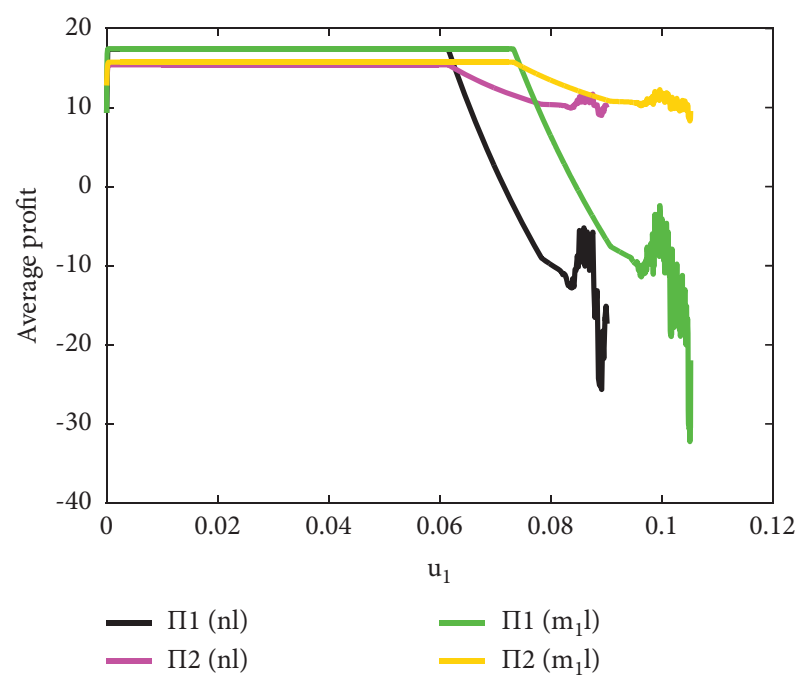

(a)

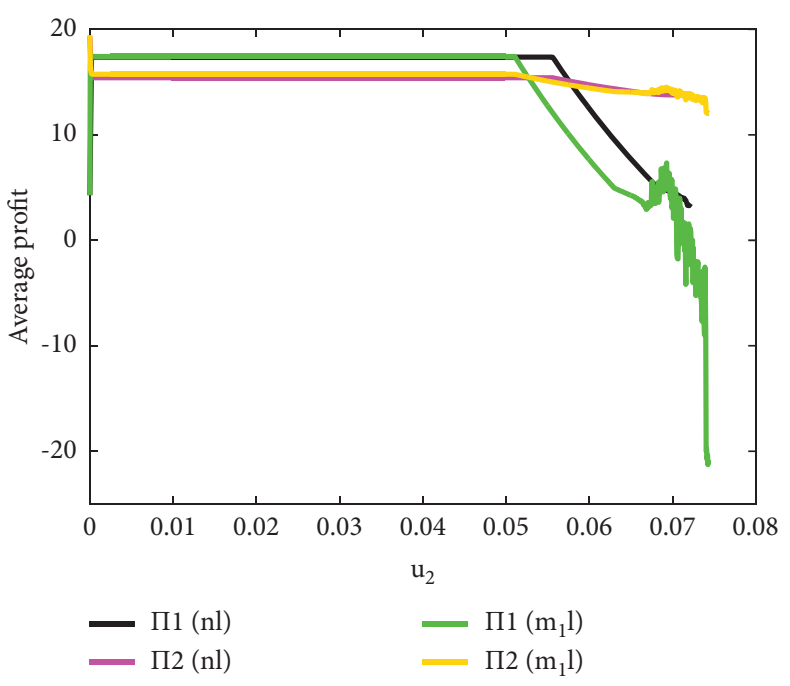

(b)

Figure 7: Change of average profit with respect to $u_{i}(i=1,2)$. (a) $u_{2}=0.02$ and (b) $u_{1}=0.02$.

Figures $8(\mathrm{a})$ and $8(\mathrm{~b})$ are the one-dimensional bifurcation diagrams of the manufacturer's profit. From Figure 8(a), it can be observed that the profit of $m_{1}$ in the chaotic state is less than or equal to the profit in the stable state. And, there are more profits at a negative value. However, we can get from Figure 8 (b) that in the chaotic state, the profit of $m_{2}$ is partly greater than the profit in the stable state of the system and the negative profit is less.

From the above analysis, we can get that, first of all, bifurcation and chaos means that there is vicious competition in the system, which will have a bad impact on the entire market. Secondly, when the system is in a state of chaos, it is even more unfavorable for $m_{1}$ who carry out lowcarbon production innovation. In the chaotic state, profits are more sensitive to changes in $u_{1}$ than to changes in $u_{2}$. Finally, for managers, they should avoid losing profits when the system enters a state of chaos. In order to keep the system stable, $m_{1}$ price adjustment speed is slower than carbon emission adjustment speed.

5.2. Impact of $p_{c}$ on Profit. In this section, we get the simulation analysis of the influence of $u_{1}$ and $p_{c}$ on profit. Figures 9(a) and 9(b) show that the profit of $m_{1}$ is affected by the parameters $p_{c}$ and $u_{1}$ in the two market power structures. Figures 9 (c) and $9(d)$ show that the profit of $m_{2}$ is affected by the parameters $p_{c}$ and $u_{1}$ in the two market power structures. We can observe from Figure 9 that as the parameter $p_{c}$ increases, the stability region of profit decreases. The analysis results are the same as in Figure 6. The change of $p_{c}$ will not make the system enter chaos. The value of $p_{c}$ satisfies the assumptions of the model. In the stable state, with the increase of $p_{c}$, manufacturers' profit increases. In the chaotic state, with the increase of $p_{c}$, the profit of $m_{2}$ has an increasing trend from negative to positive. The profit of $m_{1}$ is more complicatedly affected by $p_{c}$. With the growth of $p_{c}$, it may fluctuate in a positive direction or a negative direction.
From Figure 10, when the market is in the stable state, the total carbon emissions of manufacturers are greater than the government's carbon allowances. When market competition enters chaos, we can observe from Figure 4(a) that the price fluctuations of LP are greater than that of NLP. LP's low prices lead to increased sales, resulting in an increase in the total carbon emissions of $m_{1}$. The increase in demand for LP affects the decrease in market demand for NLP and ultimately leads to $m_{2}$ carbon emission less than $m_{1}$. Therefore, in Figure 9, in the chaotic state, as the carbon price increases, it is more beneficial to $m_{2}$. However, $m_{1}$ may eventually withdraw from the market due to vicious competition. The government should reduce carbon cap for nonlow-carbon product manufacturers and increase carbon cap for low-carbon manufacturers. And, to avoid the occurrence of similar electric vehicle fraud, the government needs to confirm the company's product production and low-carbon technology.

\section{Initial Sensitivity Analysis and Singular Attractors}

Singular attractors are the result of the interaction between global stability and local instability. It is another characteristic of system chaos. It has a self-similarity and a fractal structure [45]. Figure 11 shows the formation of a singular attractor for $n l$ systems. The attractor forming process of the $m_{1} l$ system is the same as that of the $n l$ system, so we only analyze the attractor forming process of the $n l$ system. The number and structure of attractors will change with the change of parameters $u_{1}$. There are two attractors in Figure 11(a), and the system is in a 2-period orbit. From Figures 11(a) to 11(b), we found that when $u_{1}$ increases, the attractor becomes larger. At this time, the system is in a state of chaos. From (b) to (c), the attractor is forced to become some small attractors as $u_{1}$ increases, which is a phase-locking process. Figure 11(d) shows the final chaotic attractor. It means that the manufacturers in the system enter into the chaotic competition. 


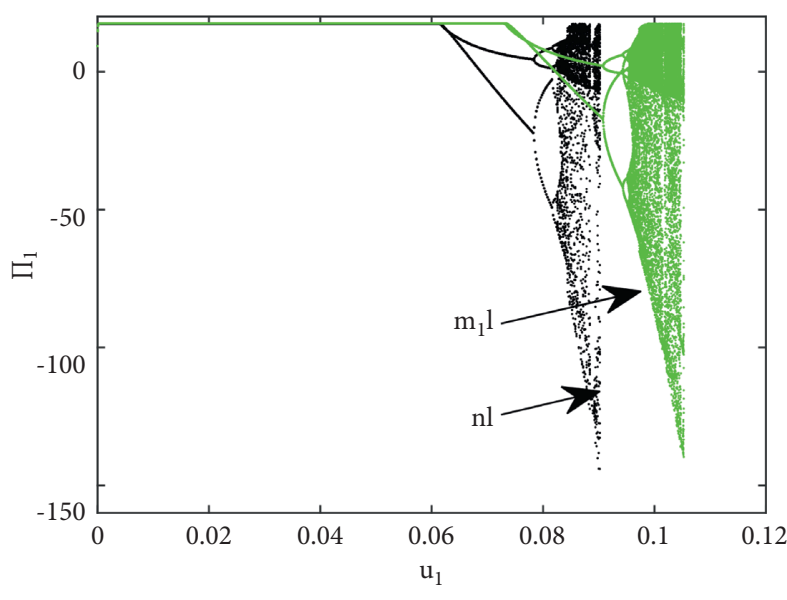

(a)

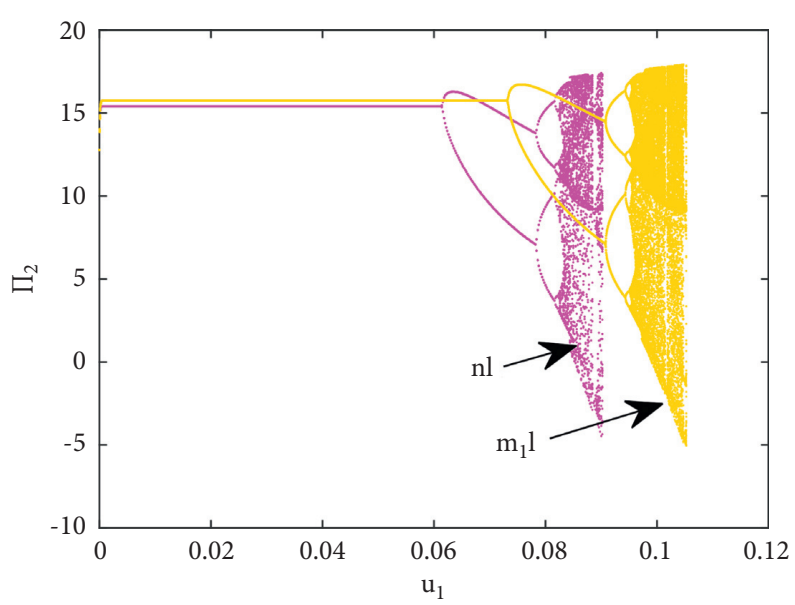

(b)

FIGURE 8: Bifurcation diagram of the profit with varying $u_{1}$ when $u_{2}=0.02$.

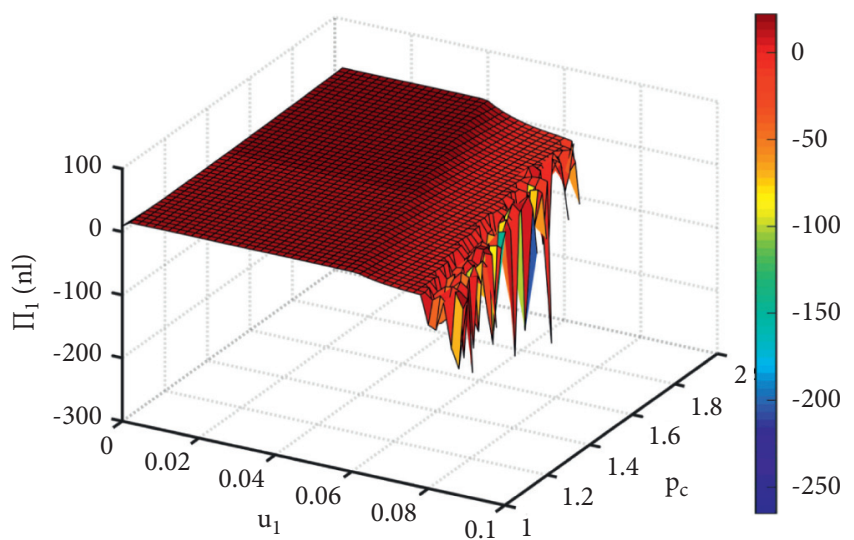

(a)

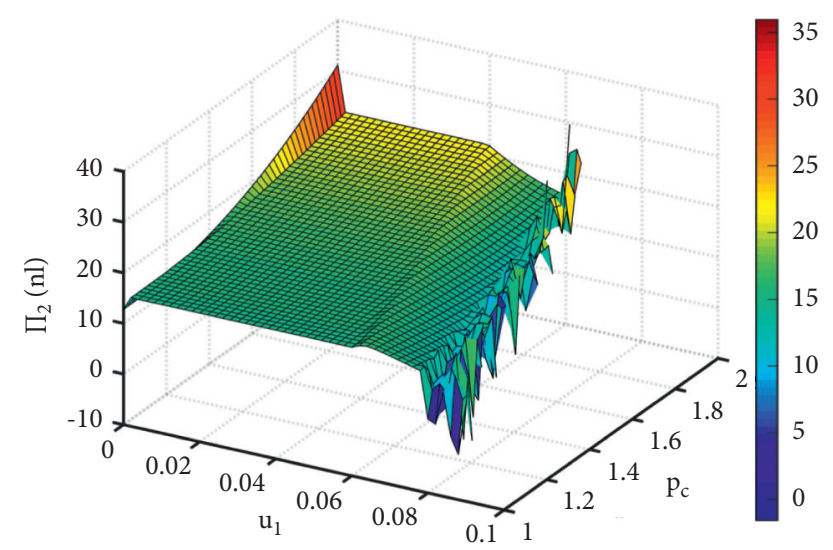

(c)

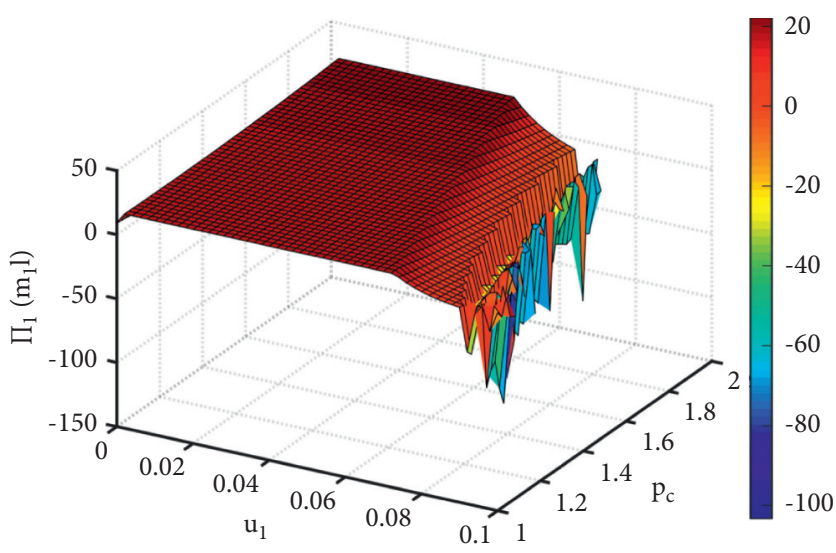

(b)

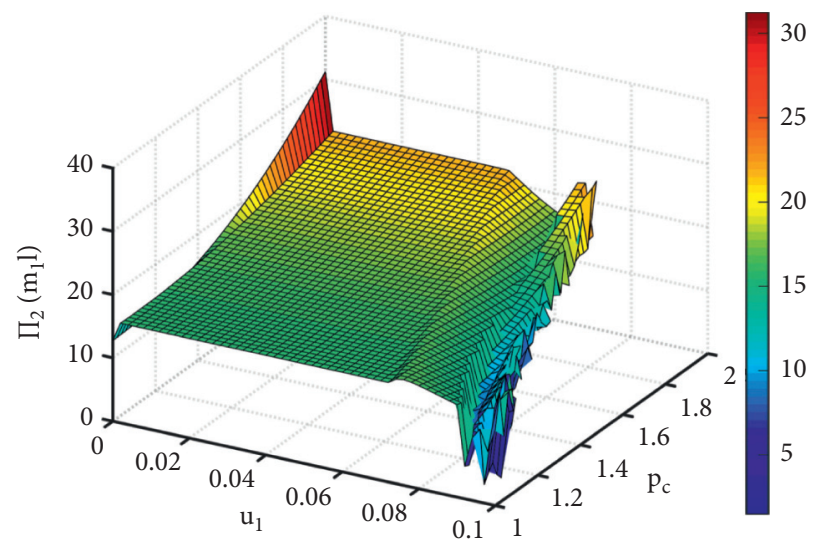

(d)

FIGURE 9: Change of profits with respect to $u_{1}$ and $p_{c}$ when $u_{2}=0.02(\mathrm{a}-\mathrm{d})$.

Through the attractor evolution process, we can observe the influence of the change of $u_{1}$ parameter on the final behaviour of the system. When one of the manufacturers increases the adjustment speed of the equilibrium decision, it causes the whole system to change in equilibrium. Due to the sensitivity of the dynamical system, small changes in parameters will be amplified, leading to the chaotic state of the system.

Figure 12 is a time series diagram of system state variables changing with time in a chaotic state. From Figures 11 and 12 , we can observe the chaotic characteristics of the system-boundedness and ergodicity. That is, the trajectory of 


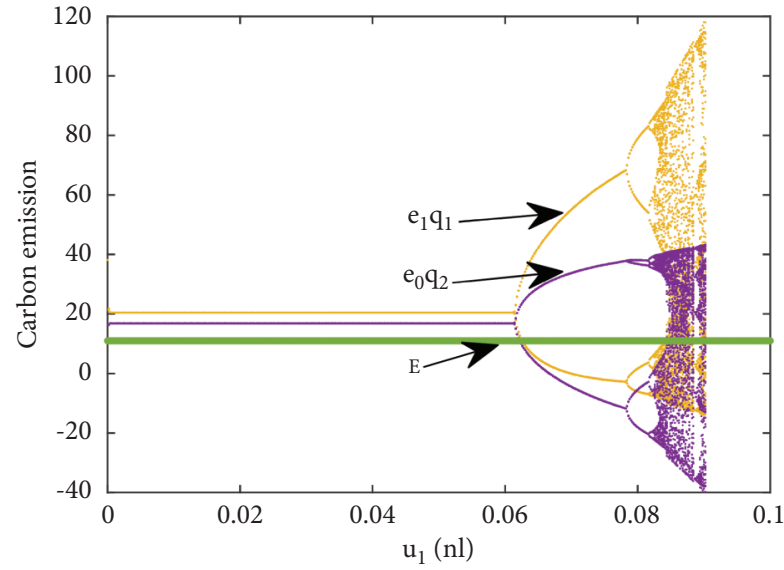

(a)

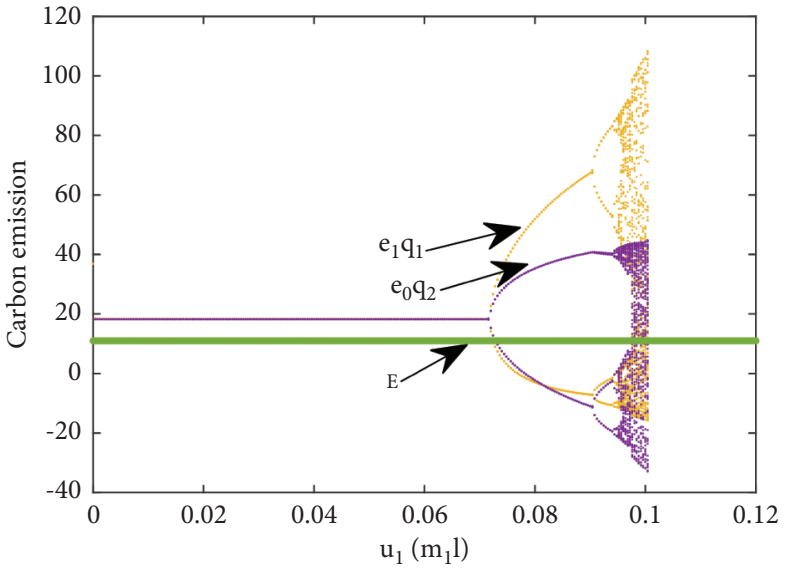

(b)

FIGURE 10: Change of carbon emission with varying $u_{1}$ when $u_{2}=0.02(\mathrm{a}, \mathrm{b})$.

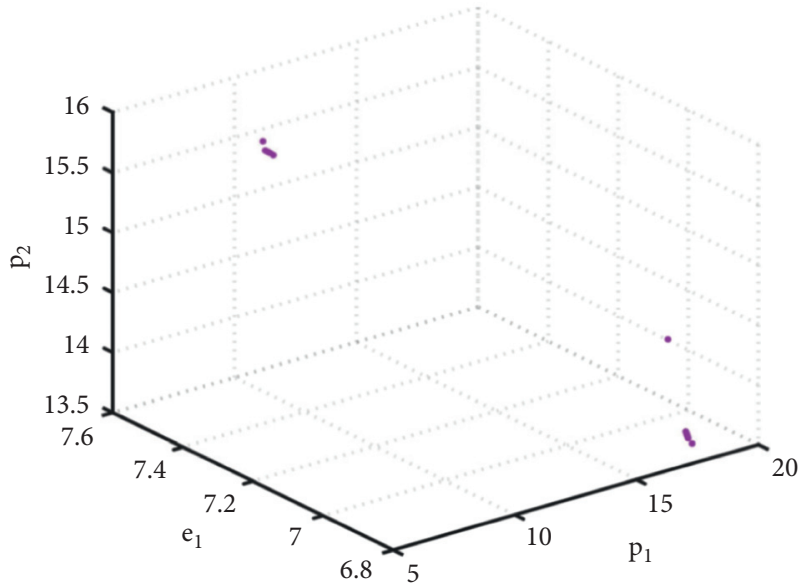

(a)

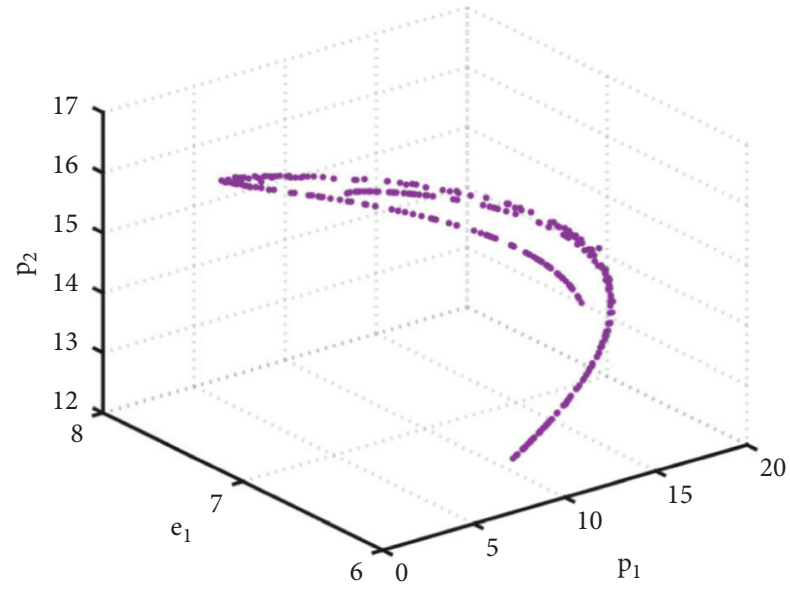

(c)

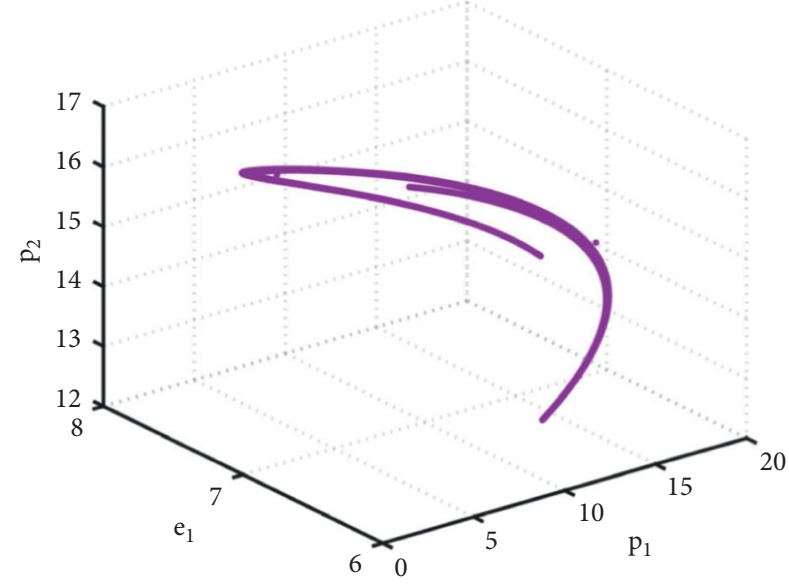

(b)

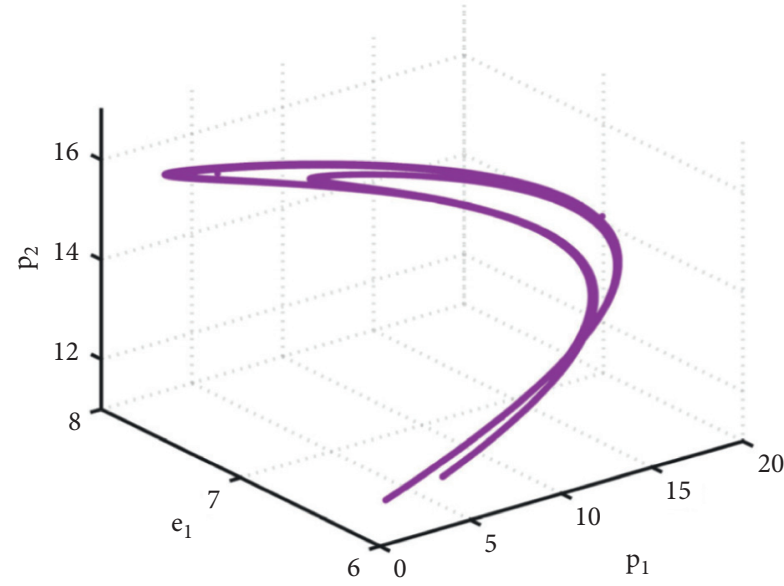

(d)

FIGURE 11: $n l$ singular attractors with $u_{2}=0.02$. (a) $u_{1}=0.0772$, (b) $u_{1}=0.087$, (c) $u_{1}=0.089$, and (d) $u_{1}=0.094$.

the system variable is always limited to the chaotic attraction region. No matter how unstable the chaotic system is, it can traverse the entire value area with time, but the system variable trajectory will not go out of the attracting region.
Combining Figures 12(a) and 4(a), we can find that the price of LP (the blue line in the figure) fluctuates between $[2,20]$ in the chaotic state. The time series of other variables have the same state. In a finite time, the chaotic trajectory passes 


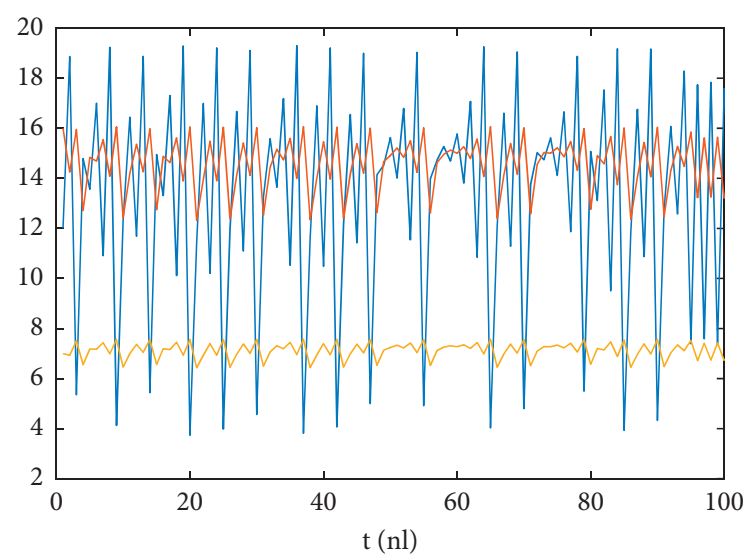

$-\mathrm{p}_{1}$
$-\mathrm{p}_{2}$
$-\mathrm{e}_{1}$

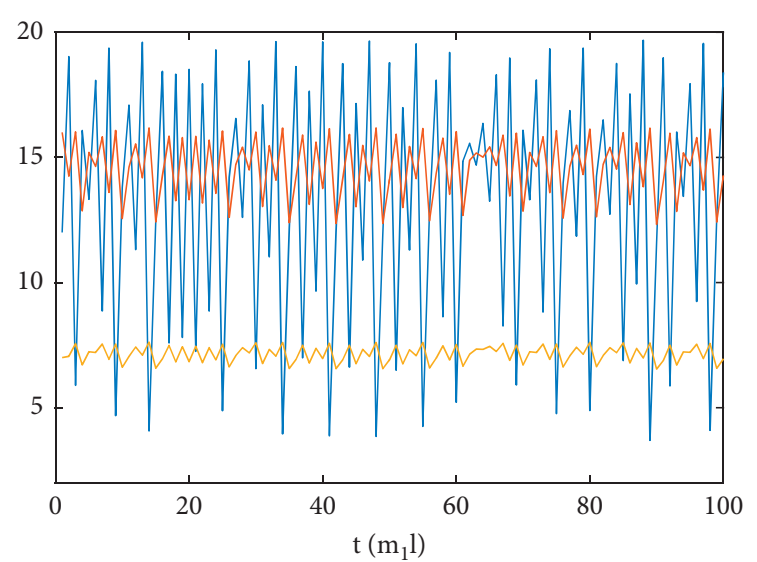

$-\mathrm{p}_{1}$
$-\mathrm{p}_{2}$
$-\mathrm{e}_{1}$

(a)

(b)

Figure 12: The time series of $p_{1}, p_{2}$, and $e_{1}$ when $u_{2}=0.02(\mathrm{a}, \mathrm{b})$.

through every state point in the chaotic zone, reflecting the ergodicity of chaos.

When the system is in a chaotic state, any slight change in the initial value of the decision variable will have a significant impact on the decision result. The evolution of the system is extremely sensitive to the dependence of initial values. It is clear that when the system is in a chaotic state, pricing decisions become uncertain, disordered, and unpredictable, compared to the pricing of the system in a stable condition. From Figure 13, we can get the difference between the decision variables when $p_{1}=12$ and 12.001 after the two initial conditions. When the initial decision variable changes slightly, it affects the decision variables at each moment of subsequent decision-making.

\section{Chaos Control}

When the system is in chaos, the profit of the manufacturer will be less than that in the stable state, and it is tough for the manufacturer to decide the price of the product. The manufacturer may even be forced to withdraw from the market, affecting the development of low-carbon technology. Therefore, market participants hope to control the market as soon as possible and achieve their profit goals. It is necessary to take some measures to delay or eliminate chaos and benefit the whole system. There are many methods to control chaos, namely, delayed feedback control [34, 46], variable feedback control $[47,48]$, and parameter adjustment [49]. In this section, the parameter adjustment method and delay control method are adopted to control the market prices of participants.

Firstly, use the parameter adjustment method to control the system. Set parameter $u$ to control the system. Under parameter adjustment control, we get the decision system as

$$
\left\{\begin{array}{l}
p_{1}(t+1)=(1-u)\left(p_{1}(t)+u_{1} p_{1}(t) \frac{\partial \prod_{1}(t)}{\partial p_{1}(t)}\right)+u p_{1}(t) \\
e_{1}(t+1)=(1-u)\left(e_{1}(t)+u_{2} e_{1}(t) \frac{\partial \prod_{1}(t)}{\partial e_{1}(t)}\right)+u e_{1}(t) \\
p_{2}(t+1)=(1-u) \frac{1}{2}\left(a+c+e_{0} p_{c}+p_{1}(t) \alpha-e_{0} \beta+e_{1}(t) \beta\right)+u p_{2}(t)
\end{array}\right.
$$

The control parameters can also be regarded as the manufacturer's learning ability and adaptive ability. When manufacturers meet the chaotic state of the market, they will take the initiative to adjust the price according to the market information [50]. It is crucial to select the proper control parameter $u$ for delaying bifurcation and restoring the system to a stable state. Next, we get the influence of parameter $u$ on system stability. In the $n l$ system, $u_{1}=0.09$ and $u_{2}=0.02$ are set. We can observe from Figure 14(a) that with the increase of $u$, the 


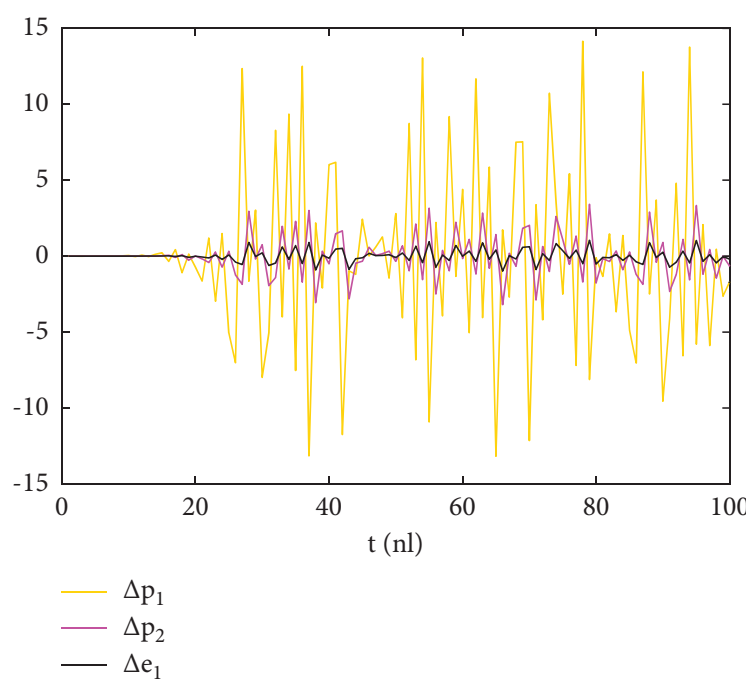

(a)

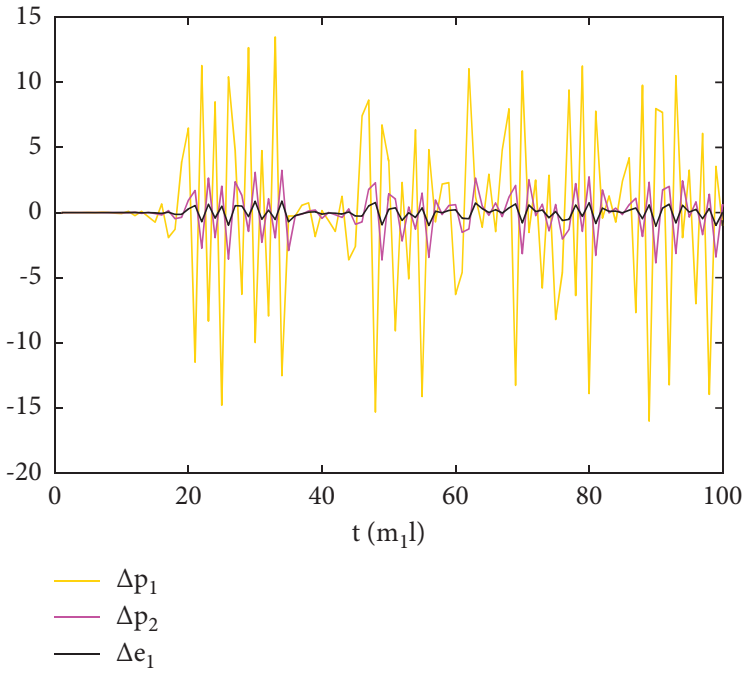

(b)

Figure 13: The sensitivity to initial value when $\left(p_{1}=12, p_{2}=16, e_{1}=7\right)$ and $\left(p_{1}=12.001, p_{2}=16, e_{1}=7\right)$ with (a) $u_{1}=0.088$ and $(\mathrm{b})$ $u_{1}=0.104$.

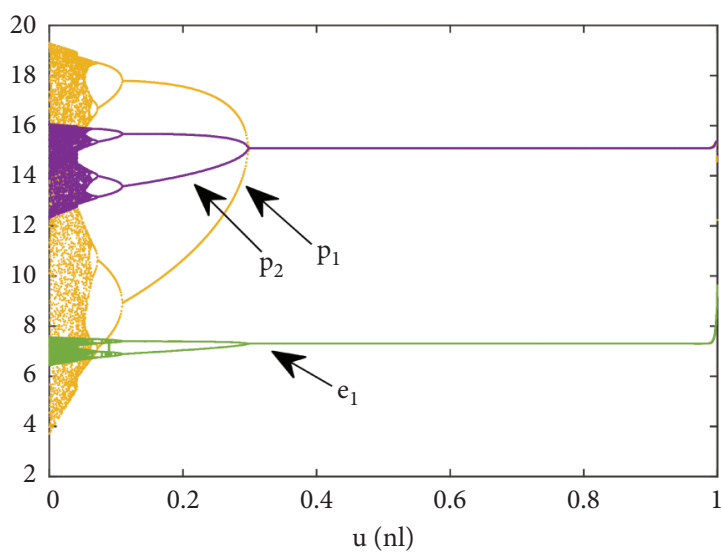

(a)

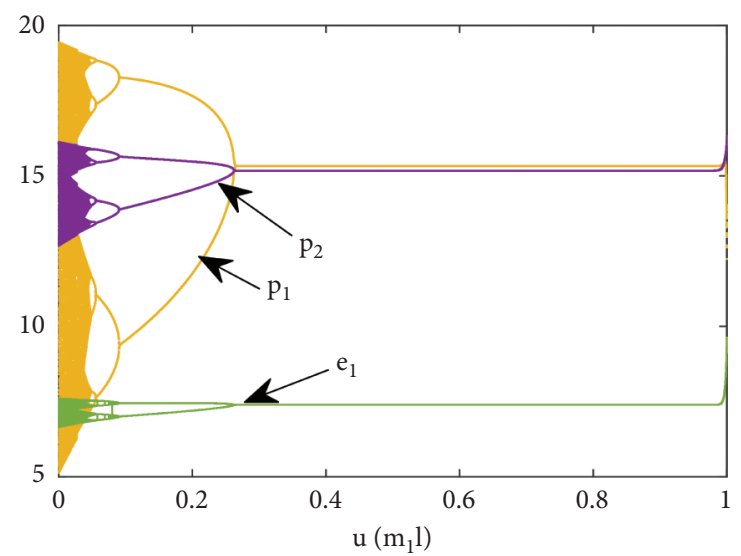

(b)

Figure 14: Bifurcation diagram with $u$ increasing (a, b).

controlled system changes from chaos to a stable state. In the $m_{1} l$ system, $u_{1}=0.1$ and $u_{2}=0.02$ are set. Figure $14(\mathrm{~b})$ is the control diagram of $m_{1} l$ system. Similarly, with the increase of $u$, the controlled system changes from chaos to a stable state.

From Figure 14(a), we can observe when $u=0.2$, the $n l$ system is controlled in the 2-period orbit. At this time, the price time series diagram of the system is shown in Figure $15(\mathrm{a})$. When $u>0.3$, the system enters a stable state. Figure 15(b) is the time series diagram of the $n l$ system when $u=0.35$. We can get that the system is controlled in 1-period orbit with $u=0.35$. The simulation results show that the parameter adjustment method can effectively control the system.

Then, we use the delayed feedback control method to control the system. Compare the control efficiency of delayed feedback and parameter adjustment methods. It is the same as the comparison of chaos control research methods in [49] literature. Set the $v$ as the control parameter and consider the output signal of the system when making decisions in the next period of the system. The decision system can be expressed as 


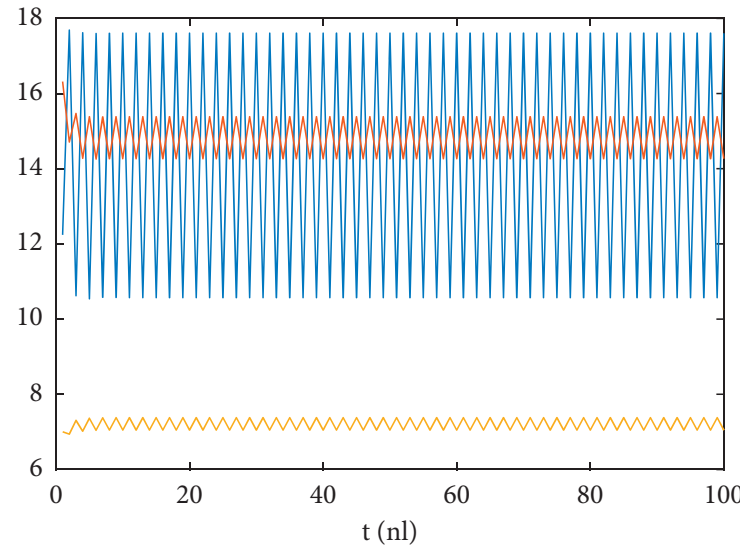

$$
\begin{aligned}
& -\mathrm{p}_{1} \\
& -\mathrm{p}_{2} \\
& -\mathrm{e}_{1}
\end{aligned}
$$

(a)

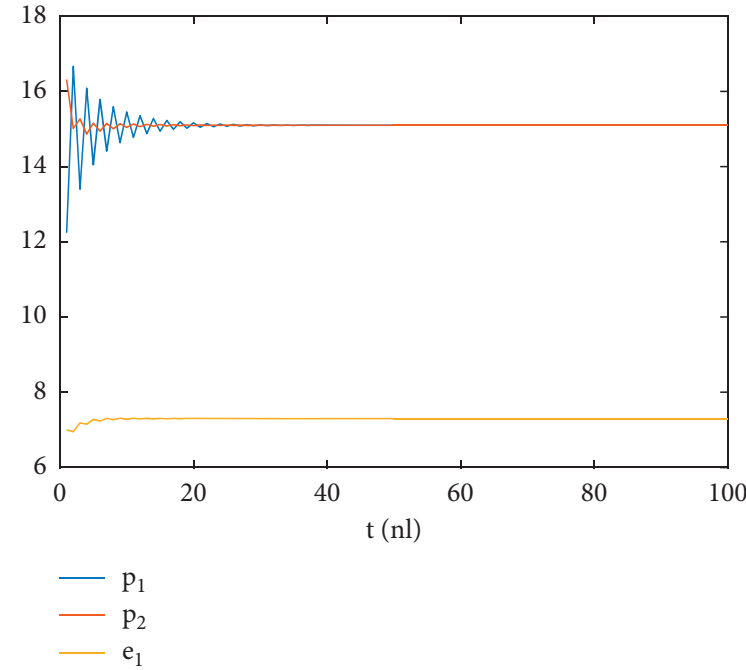

(b)

FIgURE 15: Price and carbon emission wave plot with the change of time when $u_{1}=0.09$ and $u_{2}=0.02:$ (a) $u=0.2$ and (b) $u=0.35$.

$$
\left\{\begin{array}{l}
p_{1}(t+1)=p_{1}(t)+u_{1} p_{1}(t) \frac{\partial \prod_{1}(t)}{\partial p_{1}(t)}+v\left(p_{1}(t+1)-p_{1}(t)\right), \\
e_{1}(t+1)=e_{1}(t)+u_{2} e_{1}(t) \frac{\partial \prod_{1}(t)}{\partial e_{1}(t)}+v\left(e_{1}(t+1)-e_{1}(t)\right), \\
p_{2}(t+1)=\frac{1}{2}\left(a+c+e_{0} p_{c}+p_{1}(t) \alpha-e_{0} \beta+e_{1}(t) \beta\right)+v\left(p_{2}(t+1)-p_{2}(t)\right) .
\end{array}\right.
$$

We show the simulation analysis of the system (30) in Figure 16, and the parameter settings are the same as the simulation parameters of the system (30). We can get from Figure 16 that the delayed feedback method can not effectively control the two nonlinear systems in this paper. This is contrary to the research results of chaos control in [49], which means that we cannot consider that the efficiency of the delayed feedback control method is higher than that of the parameter adjustment control method.

\section{Results and Discussion}

This study investigated the dynamic evolution of pricing decisions for low-carbon and nonlow-carbon products with different market power structures under the influence of government carbon trading. At the same time, we analyzed the effects of changes in decision-making adjustment factors, consumer environmental awareness, and low-carbon innovation cost.

Through the solution and simulation analysis of the model, we can obtain the following:

(1) When low-carbon products compete with nonlowcarbon products, low-carbon product manufacturers, as market pricing leaders, are not conducive to the proliferation of low-carbon products and the promotion of low-carbon technologies. At the same time, in the unbalanced market, the low-carbon product's carbon emission decision-making adjustment stability range is smaller than that of the balanced market.When market competition enters chaos, the price fluctuation range and the average profit of low-carbon products are greater than that of nonlow-carbon products, which is even more detrimental to the development of low-carbon industries.

Faced with the pressure of government policies and the environment, competition among manufacturers has emerged on a new track and divided in new market areas. For example, TCL became China's first electrical product (liquid crystal TV) carbon label evaluation certification manufacturer. Having a leading position in the pricing of low-carbon products is conducive to the profits of low-carbon manufacturer. However, the government and market participants may overlook that in the price competition between low-carbon products and nonlowcarbon products, and the leading position of lowcarbon companies in pricing is not conducive for the proliferation of low-carbon products and the development of low-carbon technologies.

(2) Increasing carbon prices and increasing consumer environmental awareness are more conducive to the stability of carbon emissions from low-carbon products. But it is not conducive for the stability of 


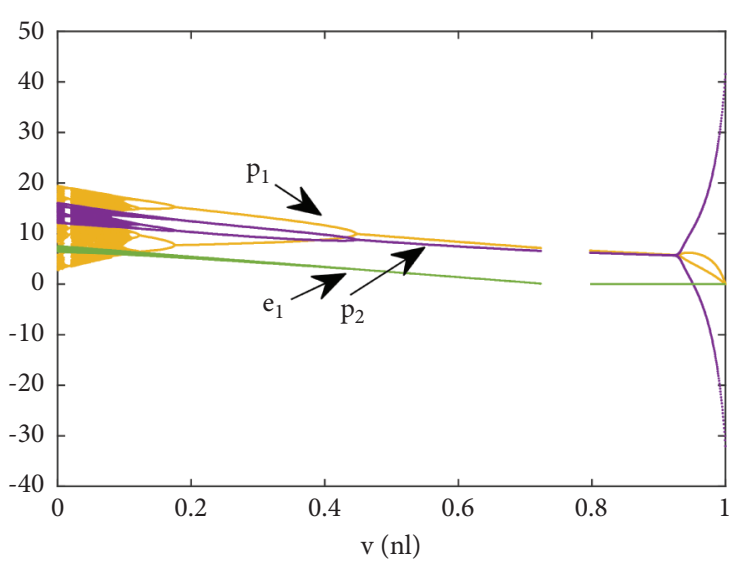

(a)

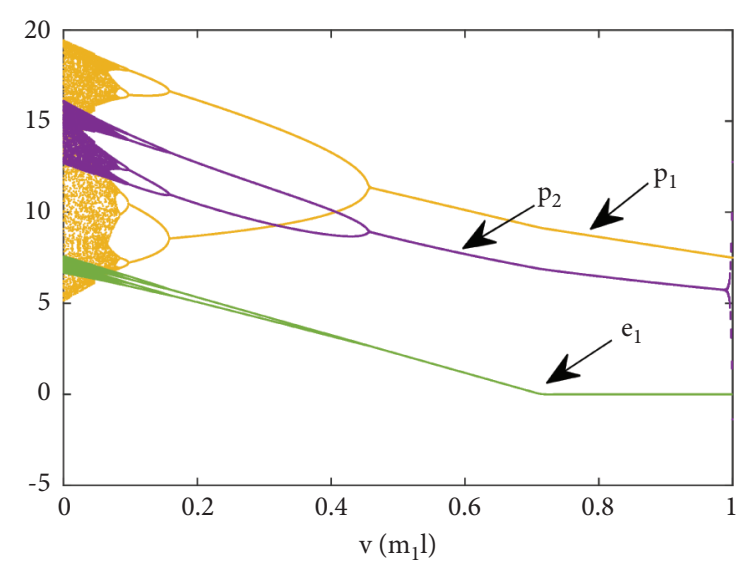

(b)

FIGURE 16: Bifurcation diagram with $v$ increasing.

low-carbon product prices. The increase in the cost of low-carbon technology reduces the stability range of decision-making speed for low-carbon product prices and carbon emissions. The speed stability range of carbon emissions decision-making is more sensitive to changes in the cost of low-carbon technologies. Controlling the speed of price adjustment and carbon emission adjustment within a stable range can ensure healthy market competition and avoid chaos and economic loses.

During the transition period of low-carbon technology, enterprises are likely to face a funding gap due to turbulent market demand and competition in the industry. Sufficient market competition and establishing a complete low-carbon technology financing guarantee system are essential methods to promote the sustainable and stable development of low-carbon technology and products.
(3) Finally, we find that for the discrete system in this paper, the parameter adjustment control method can effectively control the system, but the variable feedback control method cannot realize the effective control of the system.

The model in this paper lacks consideration of the influence of the existence of retailers on prices, and the influence of direct sales and distribution channels on prices. In addition, due to the consideration of duopoly manufacturers of the same strength, the government's carbon cap is set as a unified carbon quota and the different manufacturing strengths of enterprises are ignored. Our paper presents certain limitations that provide directions for future research.

\section{Appendix}

\section{A. Details of Complex Equation (6)}

The unspecified equation in equation (6) is equal to

$$
\begin{aligned}
& A_{1}^{n l}=a(2+\alpha)\left(p_{c}\left(p_{c}+\beta\right)-2 \gamma\right), \\
& A_{2}^{n l}=e_{0}\left(p_{c}-\beta\right)\left(p_{c} \alpha\left(p_{c}+\beta\right)-2(2+\alpha) \gamma\right), \\
& A_{3}^{n l}=2 e_{0} \beta\left(p_{c}\left(p_{c}+\beta\right)-(2+\alpha) \gamma\right), \\
& A_{4}^{n l}=c\left(2(2+\alpha) \gamma-\left(p_{c}+\beta\right)\left(p_{c} \alpha+2 \beta\right)+\alpha \beta\left(p_{c}+\beta\right)\right), \\
& B_{1}^{n l}=e_{0}\left(8 \gamma+\alpha\left(-p_{c}^{2}+\beta^{2}-2 \alpha \gamma\right)-2 \beta\left(p_{c}+\beta\right)\right), \\
& B_{2}^{n l}=a(2+\alpha)\left(p_{c}+\beta\right)+c\left(\alpha+\alpha^{2}-2\right)\left(p_{c}+\beta\right), \\
& C_{1}^{n l}=c\left(2(2+\alpha) \gamma+\beta\left(p_{c}+\beta\right)-\left(p_{c}+\beta\right)\left(p_{c}+\beta+\alpha \beta\right)\right), \\
& C_{2}^{n l}=e_{0}\left(\left(p_{c}-\beta\right)\left(2(2+\alpha) \gamma-\left(p_{c}+\beta\right)^{2}\right)-\beta\left(p_{c} \alpha\left(p_{c}+\beta\right)-2(2+\alpha) \gamma\right)-\beta^{2}\left(p_{c}+\beta\right)\right), \\
& C_{3}^{n l}=p_{c}^{2}(1+\alpha)-2(2+\alpha) \gamma+2 \beta^{2}+p_{c} \beta(2+\alpha+1) .
\end{aligned}
$$




\section{B. Details of Complex Equation (7)}

The unspecified equation in equation (7) is equal to

$$
\begin{aligned}
& D_{1}^{n l}=\left(a+c(\alpha-1)+e_{0} p_{c}(\alpha-1)\right)^{2}, \\
& D_{2}^{n l}=4(2+\alpha)^{2} \gamma^{2}\left(a+c(\alpha-1)+e_{0} p_{c}(\alpha-1)\right)^{2}, \\
& D_{3}^{n l}=E p_{c}\left(p_{c}^{2}\left(\alpha^{2}-2\right)-2\left(\alpha^{2}-4\right) \gamma+\beta^{2}(\alpha-2)+p_{c} \beta(-4+\alpha(\alpha+1))\right)^{2} .
\end{aligned}
$$

\section{Details of complex equation (19)}

The unspecified equation in equation (19) is equal to

$$
\begin{aligned}
& A_{1}^{m_{1} l}=-a(2+\alpha)\left(p_{c}^{2}\left(\alpha^{2}-2\right)+4 \gamma+p_{c} \beta(\alpha-2)\right), \\
& A_{2}^{m_{1} l}=c\left(-p_{c}^{2} \alpha\left(\alpha^{2}-2\right)+4(\alpha-2)(1+\alpha) \gamma+p_{c}(\alpha-2)(1+\alpha) \beta(\alpha-2)+\beta^{2}(\alpha-2)^{2}\right), \\
& A_{3}^{m_{1} l}=e_{0}\left(-p_{c}^{3} \alpha\left(\alpha^{2}-2\right)+p_{c}^{2} \beta\left(\alpha^{3}+4-3 \alpha^{2}\right)+p_{c}\left(-2 \alpha \beta^{2}+4(\alpha-2)(1+\alpha) \gamma+\left(4+\alpha^{2}\right) \beta^{2}-2 \alpha \beta^{2}\right)\right), \\
& B_{1}^{m_{1} l}=-a(2+\alpha)\left(p_{c}\left(-2+\alpha^{2}\right)+\beta(\alpha-2)\right), \\
& B_{2}^{m_{1} l}=c\left(\alpha^{2}+\alpha-2\right)\left(p_{c}\left(2-\alpha^{2}\right)+\beta(\alpha-2)\right), \\
& B_{3}^{m_{1} l}=e_{0}\left(-p_{c}^{2} \alpha\left(\alpha^{2}-2\right)+p_{c} \beta\left(\alpha^{3}+4-3 \alpha^{2}\right)+4\left(\beta^{2}-4 \gamma\right)+\alpha^{2}\left(8 \gamma+\beta^{2}\right)-4 \alpha \beta^{2}\right), \\
& C_{1}^{m_{1} l}=c\left(-p_{c}^{2}\left(\alpha^{2}-2\right)+2\left(-2+\alpha\left(\alpha^{2}+\alpha-2\right)\right) \gamma-p_{c} \beta((\alpha-1) \alpha(2+\alpha-1)-2)-\beta^{2}(1+\alpha-1)(\alpha-2)\right), \\
& C_{2}^{m_{1} l}=\left(p_{c}^{2}(1+\alpha)\left(-2+\alpha^{2}\right)+8 \gamma-2(\alpha-2) \alpha \gamma-6 p_{c} \beta+2 \beta^{2}(\alpha-2)+p_{c} \alpha \beta(-1+\alpha++2 \alpha)\right), \\
& C_{3}^{m_{1} l}=e_{0}\left(-p_{c}^{3}\left(-2+\alpha^{2}\right)+p_{c}^{2} \beta\left(2+\alpha-\alpha^{3}\right) .\right.
\end{aligned}
$$

\section{Data Availability}

The data used to support the findings of this study are included within the article.

\section{Conflicts of Interest}

The authors declare that no conflicts of interest.

\section{Acknowledgments}

This research was supported in part by the National Natural Science Foundation of China (grant no. 71371124).

\section{References}

[1] S. An, B. Li, D. Song, and X. Chen, "Green credit financing versus trade credit financing in a supply chain with carbon emission limits," European Journal of Operational Research, vol. 292, no. 1, pp. 125-142, 2021.

[2] R. Danish, R. Ulucak, S. U. D. Khan, M. A. Baloch, and N. Li, "Mitigation pathways toward sustainable development: is there any trade off between environmental regulation and carbon emissions reduction?" Sustainable Development, vol. 28, no. 4, pp. 813-822, 2020.
[3] B. Sarkar, M. Sarkar, and B. Ganguly, "Combined effects of carbon emission and production quality improvement for fixed lifetime products in a sustainable supply chain management," International Journal of Production Economics, vol. 231, 2021.

[4] B. Zhang and L. Xu, "Multi-item production planning with carbon cap and trade mechanism," International Journal of Production Economics, vol. 144, no. 1, pp. 118-127, 2013.

[5] Y. Shen, Z.-W. Su, and M. Y. Malik, "Does green investment, financial development and natural resources rent limit carbon emissions? A provincial panel analysis of China," The Science of the Total Environment, vol. 755, 2021.

[6] J. Li, Y. Zhang, and Y. Tian, "Reduction of carbon emissions from China's coal-fired power industry: insights from the province-level data," Journal of Cleaner Production, vol. 242, 2020.

[7] S. Arora and S. Gangopadhyay, "Toward a theoretical model of voluntary overcompliance," Journal of Economic Behavior \& Organization, vol. 28, no. 3, pp. 289-309, 1995.

[8] S. Bansal and S. Gangopadhyay, "Tax/subsidy policies in the presence of environmentally aware consumers," Journal of Environmental Economics and Management, vol. 45, no. 2, 2003.

[9] D. Ghosh, J. Shah, and S. Swami, "Product greening and pricing strategies of firms under green sensitive consumer 
demand and environmental regulations," Annals of Operations Research, vol. 290, no. 1-2, pp. 491-520, 2020.

[10] P. Li, C. Rao, and M. Goh, "Pricing strategies and profit coordination under a double echelon green supply chain," Journal of Cleaner Production, vol. 278, 2021.

[11] J. Jian, Y. Zhang, and L. Jiang, "Coordination of supply chains with competing manufacturers considering fairness concerns," Complexity, vol. 2020, Article ID 4372603, 11 pages, 2020.

[12] S. S. Sana, "A structural mathematical model on two echelon supply chain system," Annals of Operations Research, vol. 20, 2021.

[13] S. S. Sana, "Price competition between green and non green products under corporate social responsible firm," Journal of Retailing and Consumer Services, vol. 55, 2020.

[14] X. Chen and G. Hao, "Sustainable pricing and production policies for two competing firms with carbon emissions tax," International Journal of Production Research, vol. 53, no. 21, pp. 6408-6420, 2015.

[15] H. Sun and J. Yang, "Optimal decisions for competitive manufacturers under carbon tax and cap-and-trade policies," Computers \& Industrial Engineering, vol. 156, 2021.

[16] G. Yang, G. Ji, and K. H. Tan, "Impact of regulatory intervention and consumer environmental concern on product introduction," International Journal of Production Economics, vol. 230, 2020.

[17] P. Zhou and W. Wen, "Carbon-constrained firm decisions: from business strategies to operations modeling," European Journal of Operational Research, vol. 281, no. 1, pp. 1-15, 2020.

[18] M.-L Liu, Z.-H Li, S. Anwar, and Y. Zhang, "Supply chain carbon emission reductions and coordination when consumers have a strong preference for low-carbon products," Environmental Science and Pollution Research, vol. 28, no. 16, pp. 19969-19983, 2021.

[19] M. Jian, H. He, C. Ma, Y. Wu, and H. Yang, "Reducing greenhouse gas emissions: a duopoly market pricing competition and cooperation under the carbon emissions cap," Environmental Science and Pollution Research, vol. 26, no. 17, pp. 16847-16854, 2019.

[20] Z. Luo, X. Chen, and X. Wang, "The role of co-opetition in low carbon manufacturing," European Journal of Operational Research, vol. 253, no. 2, pp. 392-403, 2016.

[21] Y. C. Pan, J. Hussain, and X. Y. Liang, "A duopoly game model for pricing and green technology selection under cap-andtrade scheme," Computers \& Industrial Engineering, vol. 153, 2021.

[22] R. Zhang, B. Liu, and W. Wang, "Pricing decisions in a dual channels system with different power structures," Economic Modelling, vol. 29, no. 2, pp. 523-533, 2012.

[23] X. Chen, X. Wang, and X. Jiang, "The impact of power structure on the retail service supply chain with an $\mathrm{O} 2 \mathrm{O}$ mixed channel," Journal of the Operational Research Society, vol. 67, no. 2, pp. 294-301, 2016.

[24] A. Chakraborty and P. Mandal, "Channel efficiency and retailer tier dominance in a supply chain with a common manufacturer," European Journal of Operational Research, vol. 294, no. 1, pp. 100-121, 2021.

[25] X. Chen, Z. Luo, and X. Wang, "Impact of efficiency, investment, and competition on low carbon manufacturing," Journal of Cleaner Production, vol. 143, pp. 388-400, 2017.

[26] W. Lou and J. Ma, "Complexity of sales effort and carbon emission reduction effort in a two-parallel household appliance supply chain model," Applied Mathematical Modelling, vol. 64, pp. 398-425, 2018.
[27] L. Fanti, L. Gori, C. Mammana, and E. Michetti, "The dynamics of a Bertrand duopoly with differentiated products: synchronization, intermittency and global dynamics," Chaos, Solitons \& Fractals, vol. 52, pp. 73-86, 2013.

[28] Y. Wang and G. Hou, "A duopoly game with heterogeneous green supply chains in optimal price and market stability with consumer green preference," Journal of Cleaner Production, vol. 255, 2020.

[29] E. Ahmed, A. A. Elsadany, and T. Puu, "On Bertrand duopoly game with differentiated goods," Applied Mathematics and Computation, vol. 251, pp. 169-179, 2015.

[30] X. Xi and J. Zhang, "Complexity analysis of a decision-making game concerning governments and heterogeneous agricultural enterprises with bounded rationality," Chaos, Solitons \& Fractals, vol. 140, 2020.

[31] A. A. Elsadany, "Dynamics of a Cournot duopoly game with bounded rationality based on relative profit maximization," Applied Mathematics and Computation, vol. 294, pp. 253-263, 2017.

[32] P. T. Zhang, "Chaos in duopoly pricing," Pergamon, vol. 1, no. 6, 1991.

[33] Q. Li, M. Li, and Y. Huang, "Dynamic investigation in green supply chain considering channel service," Complexity, vol. 2020, Article ID 1640724, 7 pages, 2020.

[34] L. Zhao and J. Zhang, "Analysis of a duopoly game with heterogeneous players participating in carbon emission trading," Nonlinear Analysis Modelling and Control, vol. 19, no. 1, pp. 118-131, 2014.

[35] J. H. Ma, Y. M. Hou, and Z. X. Wang, "Pricing strategy and coordination of automobile manufacturers based on government intervention and carbon emission reduction," Energy Policy, vol. 148, 2021.

[36] Q. Peng, C. Wang, and L. Xu, "Emission abatement and procurement strategies in a low-carbon supply chain with option contracts under stochastic demand," Computers \& Industrial Engineering, vol. 144, 2020.

[37] P. He, Z. Wang, V. Shi, and Y Liao, "The direct and cross effects in a supply chain with consumers sensitive to both carbon emissions and delivery time," European Journal of Operational Research, vol. 292, no. 1, pp. 172-183, 2021.

[38] S. C. Choi, "Price competition in a channel structure with a common retailer," Marketing Science, vol. 10, no. 4, 1991.

[39] C.-F. Zhu and Q.-R. Wang, "Chaotic behaviors in a nonlinear game of two-level green supply chain with government subsidies," Complexity, vol. 2020, Article ID 6645506, 11 pages, 2020.

[40] Q. Li, Y. Zhang, and Y. Huang, "The impacts of fairness concern and different business objectives on the complexity of dual-channel value chains," Complexity, vol. 202013 pages, 2020.

[41] S. S. Askar, "Duopolistic Stackelberg game: investigation of complex dynamics and chaos control," Operational Research, vol. 20 , no. 3, pp. 1685-1699, 2020.

[42] J. Ma, F. Zhang, and H. Jiang, "Dynamic pricing game under different channel power structures in a closed-loop supply chain," International Journal of Bifurcation and Chaos, vol. 30, no. 4, 2020.

[43] T. Li, D. Yan, and X. Ma, "Stability analysis and chaos control of recycling price game model for manufacturers and retailers," Complexity, vol. 2019, 2019.

[44] J. Ma and L. Xie, "The comparison and complex analysis on dual-channel supply chain under different channel power structures and uncertain demand," Nonlinear Dynamics, vol. 83, no. 3, pp. 1379-1393, 2016. 
[45] S. S. Askar, "On comparing between two nonlinear Cournot duopoly models," Complexity, vol. 2021, 2021.

[46] K. Pyragas, "Continuous control of chaos by self-controlling feedback," Physics Letters A, vol. 170, no. 6, pp. 421-428, 1992.

[47] J. Ma and J. Zhang, "Price game and chaos control among three oligarchs with different rationalities in property insurance market," Chaos, vol. 22, no. 4, p. 043120, 2012.

[48] J. Zhou and X. Chen, "The impact of service and channel integration on the stability and complexity of the supply chain," Complexity, vol. 2020, Article ID 8178947, 9 pages, 2020.

[49] X. Zhan, Y. Tian, and C. Liu, "Study of the complexity game of supply chain green innovation introduction under EPR policy and government subsidies," Complexity, vol. 2020, Article ID 5342606, 12 pages, 2020.

[50] X. Ma, C. Bao, and L. Su, "Analysis of complex dynamics in different bargaining systems," Complexity, vol. 2020, Article ID 8406749, 11 pages, 2020. 